\title{
Your spouse is fired! How much do you care?
}

\author{
Milena Nikolova $^{1}$ (D) Sinem H. Ayhan ${ }^{2}$
}

Received: 4 September 2017 / Accepted: 21 February 2018 / Published online: 24 March 2018

(C) The Author(s) 2018

\begin{abstract}
This study is the first to provide a causal estimate of the cross-spouse subjective well-being consequences of unemployment. Using German panel data on married and cohabiting partners for 1991-2015 and information on exogenous unemployment entry due to workplace closure, we show that one spouse's unemployment experience reduces the life satisfaction of the other partner. The estimated spillover is at least one quarter of the effect of own unemployment and is equally pronounced among female and male partners. In addition, while wives' life satisfaction does not recover even two years after their partners becoming unemployed, husbands only react to their wives' joblessness during the first year of unemployment. Our results are insensitive to income controls and the couple's position in the income distribution, thus reflecting the non-pecuniary costs of unemployment. Although the income loss hardly explains the negative spillover effects of unemployment on spousal life satisfaction, we document large declines in spousal satisfaction with household income and living standards. This finding supports the argument that the costs of unemployment borne by indirectly affected spouses extend beyond the loss of consumption opportunities and might be rather related to social values attached to market work. Being robust to a battery of sensitivity checks, our findings imply that public policy programs aimed at mitigating unemployment's negative consequences need to target not only those directly affected but also cohabiting spouses.
\end{abstract}

Responsible editor: Erdal Tekin

Milena Nikolova

m.v.nikolova@rug.nl

Sinem H. Ayhan

Sinem.Ayhan@wiwi.uni-muenster.de

1 Global Economics and Management, Faculty of Economics and Business, University of Groningen, Nettelbosje 2, 9747AE Groningen, The Netherlands

2 Institut für Ökonometrie und Wirtschaftsstatistik, WWU University of Münster, Am Stadtgraben 9, 48143 Münster, Germany 
Keywords Unemployment $\cdot$ Involuntary job loss $\cdot$ Plant closures $\cdot$ Couples $\cdot$ Subjective well-being

JEL classification $\mathrm{I} 31 \cdot \mathrm{J} 01 \cdot \mathrm{J} 65$

\section{Introduction}

Economists have been devoting increasing attention to the broad well-being consequences of unemployment. ${ }^{1}$ A substantial body of literature has documented that joblessness causes large life satisfaction declines and permanently scars those directly affected (Winkelmann 2014; Clark et al. 2001). While most of the scholarship has focused on the subjective well-being consequences of one's own unemployment, it is reasonable to expect that unemployment may affect the well-being of other family members through the negative externatilities due to sharing the same household, having a common income, and being exposed to similar stressors (Luhmann et al. 2014). Similarly, one spouse's job loss could affect the well-being of the other spouse due to increased financial strain and worries about the future income, or due to non-monetary considerations, including the change in the amount of time spent together, social stigmatization, emotional contagion, and the spillover of negative emotions such as stress or worry (Luhmann et al. 2014).

Nevertheless, with a few exceptions, the literature on unemployment and well-being has surprisingly ignored explorations of the within-couple subjective well-being externalities. This paper fills this void by investigating how one spouse's exogenous unemployment induced by company closings causally affects the subjective well-being of the other partner (i.e., the indirectly affected spouse). ${ }^{2}$ Using household data from the German Socio-Economic Panel Study (GSOEP) for 1991-2015, which allow us to employ couple fixed effects, we find that spousal job loss due to workplace closure has a negative effect on the indirectly affected spouse's life satisfaction. ${ }^{3}$ By accounting for about one quarter to one third of the effect of one's own unemployment on subjective well-being, the magnitude of the cross-spouse externality that we document is economically important. In particular, following his wife's unemployment, a husband's life satisfaction decreases by about 0.34 points (on a $0-10$ scale).

\footnotetext{
${ }^{1}$ Beyond the associated long-term income declines (e.g., Couch and Placzek 2010; Davis and Wachter 2011), individual unemployment is linked with worsened physical health and mortality (e.g., Gerdtham and Johannesson 2003; Sullivan and Von Wachter 2009), mental health declines (Kuhn et al. 2009; Marcus 2013) and can increase the probability of suicide (Avdic and Chevalier 2016). Browning et al. (2006), Kuhn et al. (2009), and Schmitz (2011) find no causal effects of unemployment on physical health. However, Kuhn et al. (2009) document associated mental health effects.

2 Throughout this paper, we use the terms "spouse" and "partner" interchangeably. "Husband" is a heuristic used to designate the male partner, while "wife" denotes the female spouse. Cohabiting couples do not need to be formally married.

3 Throughout this paper, we use the terms "plant closure" and "company/workplace closure" interchangeably. Furthermore, we use the terms "unemployment" and "job loss" interchangeably.
} 
The decline is slightly smaller $(0.25$ points $)$ for the average woman whose husband loses his job, although the gender difference is statistically insignificant. Furthermore, we also discover that the life evaluations reduction is also mirrored in the declining satisfaction with household income and living standards.

In addition, we investigate the subjective well-being trajectories of partners before and after involuntary spousal unemployment. We show that wives do not adapt to their husbands' unemployment, while the pattern for indirectly affected husbands is less clear-cut. Our results are robust to several sensitivity tests, such as controlling for job loss expectations, panel attrition, partnership dissolution, state-specific shocks, and local-level unemployment rates. We also test for possible channels behind our results and conclude that the negative effect of spousal unemployment is independent of current and future income, the unemployment duration, as well as the couple's position in the income distribution. Taken together with the declining satisfaction with income and living standards, these results suggest that in a country with a liberal unemployment benefits system such as Germany, the stigma attached to living on public welfare rather than the financial concerns may account for the well-being losses that we document (Chadi and Hetschko 2017).

This paper focuses on the cognitive component of subjective well-being, namely life satisfaction. ${ }^{4}$ It thus differs from the related scholarship on the mental health consequences of spousal unemployment (e.g., Bubonya et al. 2017; Marcus 2013; Mendolia 2014; Siegel et al. 2003). At first sight, it may seem that mental health and subjective well-being are synonymous. Nonetheless, despite being conceptually related, mental health refers to the absence of depression and chronic anxiety, while life satisfaction is a global reflective assessment of one's life as a whole (Diener et al. 1999; Flèche and Layard 2017). While both mental health and life satisfaction are subjective states, mental illness is typically diagnosed by a medical professional. Finally, the correlation coefficient between mental health and misery (low subjective well-being) is as low as 0.1 (and as high as 0.4), implying that these are two different constructs (Flèche and Layard 2017). ${ }^{5}$

Building on the extant studies, our contribution to the literature is threefold. First, we provide a causal estimate of the effects of spousal unemployment on the other partner's life evaluations using representative household German panel data. Second, in addition to studying unemployment's externalities in terms of spousal life satisfaction, we are also the first to consider the consequences of unemployment for the indirectly affected partner's satisfaction with five different life domains: leisure, housework, household income, standard of living, and health. Third, we document novel results concerning the anticipation of and adaptation to spousal job loss due to plant closing and we compare and contrast these patterns with the anticipation of and adaptation to one's own unemployment due to company closure in our sample. Finally, we carefully consider the robustness of our findings and whether income considerations could be driving our results.

We argue that a causal understanding of the size of the spillover effects of unemployment has important consequences for the design of social policy. Our findings

\footnotetext{
${ }^{4}$ For further information about the other subjective well-being dimensions and their determinants, see OECD (2013); Graham and Nikolova (2015); Helliwell et al. (2016); Tay and Diener (2011).

${ }^{5}$ While mental illness explains most of the variation in low subjective well-being (i.e., misery), it is one among several determinants, including poverty, unemployment, and physical health (Flèche and Layard 2017).
} 
highlight the relevance of unemployment's within-couple externalities and expand the state-of-the-art knowledge of such interdependencies. As such, the results imply that effective public policy programs aimed at mitigating the negative consequences of unemployment should adopt a family perspective.

\section{Related literature}

Both cross-sectional and panel studies find unequivocal subjective well-being losses accruing to individuals who experience unemployment themselves (see Winkelmann (2014) for a review). ${ }^{6}$ Specifically, past unemployment experiences reduce current subjective well-being levels conditional on current labor market status (Clark et al. 2001). Even job loss expectations can be as devastating as the unemployment experience itself (Witte 1999). In addition, individuals do not adapt to unemployment in virtually every context in which this relationship has been investigated: even five years after becoming unemployment, men's life satisfaction scores continue to decline. The results for women are not so clear-cut (Clark 2016). ${ }^{7}$

Using the only cross-section from the British Household Panel Study (BHPS) available at the time, Clark and Oswald (1994) were among the first to document the negative association between personal unemployment and subjective well-being. Furthermore, Gerlach and Stephan (1996) and Winkelmann and Winkelmann (1998) furnish the first panel regression estimates demonstrating the negative life satisfaction consequences of unemployment in Germany, which amount to about one point on a 0 10 scale. The pecuniary costs of unemployment (i.e., the loss of income) are about two to seven times smaller compared to the non-monetary costs related to loss of status and work identity (Winkelmann and Winkelmann 1998; Knabe and Rätzel 2011a, b). Given the large non-pecuniary costs of job loss, the early literature concluded (yet did not formally test) that unemployment entry is largely involuntary. Indeed, as the first to distinguish between voluntary and involuntary job loss, Kassenboehmer and HaiskenDeNew (2009) find that company closures - which proxy unexpected and involuntary job loss - lead to individual life satisfaction declines of about 0.5 points on a $0-10$ scale.

Nevertheless, to date no study has examined whether and how one spouse's unemployment causally affects the other partner's subjective well-being. ${ }^{8}$ One related early contribution in the economics literature (Winkelmann and Winkelmann 1995) has

\footnotetext{
${ }^{6}$ The literature regarding the mental health consequences of one's own unemployment is more mixed. Using German data and the plant closure variable, Schmitz (2011) finds no effects of unemployment on health satisfaction or mental health. Kuhn et al. (2009) find that plant closings in Austria result in an increase in expenditures for antidepressants and an increase in hospitalizations due to mental problems for men.

${ }^{7}$ In this sense, personal unemployment is unlike any other life event. People's life satisfaction normalizes (although it may not fully recover to its initial level) after income gains and losses, marriage, divorce, the birth of a child, widowhood, and disability (Clark 2016).

${ }^{8}$ Several studies in a related body of literature examine the well-being consequences of parental unemployment for co-resident children. First, using British longitudinal data, Powdthavee and Vernoit (2013) find that parental unemployment was positive for children's happiness when the child was up to 11 years old but the effect becomes negative or insignificant later on. Using data on German adolescent children, Kind and Haisken-DeNew (2012) show that the life satisfaction of male children aged 17-25 declines following their father's unemployment. Meanwhile, Bubonya et al. (2017) find that parental unemployment only worsens female children's mental health.
} 
studied cross-spousal spillovers in life satisfaction due to unemployment. Specifically, using GSOEP data for West Germany for 1984-1989, Winkelmann and Winkelmann (1995) show one regression table whereby in addition to controlling for one's own unemployment status, the authors also include indicators for the partner's employment status. ' The study shows that conditional on one's own unemployment, partners' unemployment reduces female life satisfaction by 0.5 points (on a $0-10$ scale). Men do not experience additional declines in life satisfaction above and beyond their own unemployment. While the Winkelmann and Winkelmann (1995) work is important in highlighting the within-couple externalities of unemployment, it relies on data only from West Germany from the late-1980s and does not differentiate between voluntary and involuntary unemployment entry. Specifically, own life satisfaction or the life satisfaction of the spouse may be correlated with the unemployment entry, thus biasing upwards the coefficient estimates in Winkelmann and Winkelmann (1995).

We also point out that our paper substantively differs from Luhmann et al. (2014), who study 2973 couples in the GSOEP during the years 1984-2009 and document their life satisfaction trajectories before and after unemployment using research methods from the psychology discipline. The models that the authors use have a number of limitations. For instance, they do not have couple or individual fixed effects and as such cannot rule out individual or couple-level unobserved heterogeneity. Moreover, the paper only includes a limited number of covariates (labor status, job security worry, children, relationship duration, income gender, and age), and individuals appear in the regressions more than once as part of the same couple. The associated declines in partners' well-being is about 0.32 points on a $0-10$ scale (relative to the baseline) and the authors document anticipation effects one year before spousal unemployment and no adaptation two years following the unemployment episode.

Finally, the present study is related to but distinct from the growing body of the literature on the mental health consequences of spousal unemployment. One of the first nationally representative analyses offering a household-level perspective on unemployment uses 1987 Irish data to demonstrate that husbands' unemployment is unassociated with wives' mental health (Whelan 1994). Exploiting British panel data, Clark (2003) discovers that the negative mental well-being consequences of unemployment are partially mitigated if the spouse or other household members are also unemployed, highlighting the social norm of unemployment. Using panel data on older adults from the Health and Retirement Study, Siegel et al. (2003) find no association between husbands' job loss and wives' mental health, which is consistent with the crosssectional results of Whelan (1994). Several papers explicitly tackle the endogeneity between spousal job loss and the other partner's mental health outcomes. Specifically, based on 2002-2010 German panel data and a difference-in-differences matching estimator, Marcus (2013) finds that unemployment negatively affects own mental health as well as the mental health of the other spouse, with the latter effect being smaller. His results further suggest that the decreases in spousal mental health are larger when the husband (rather than the wife) becomes jobless. Mendolia (2014) tackles the endogeneity of job loss by focusing on redundancies in declining industries. Using a

\footnotetext{
${ }^{9}$ The same exercise is reported in Caroll (2007) using Australian panel data, who finds no statistically significant effects of partner unemployment on the odds of reporting life satisfaction scores greater than 5 (on a $1-10$ scale).
} 
logit fixed effects model and the first 14 waves of BHPS, she finds that both partners in British couples in which the man loses his job experience poor mental health. Bubonya et al. (2017) utilize Australian panel data and mitigate reverse causality problems by relying on a fixed effects analysis in combination with lagged spousal unemployment. They demonstrate that husbands' mental health does not deteriorate due to their wives' job loss. However, the mental well-being of wives declines after their husbands' unemployment, but only if the job loss episode is sustained, or couple had financial difficulties or relationship strain prior to the unemployment.

\section{Data and variables}

\subsection{Data}

We rely on the GSOEP, which is a representative household panel in Germany (version 32.1) (Frick et al. 2007; SOEP 2016). The data offer a rich set of variables related to subjective well-being, health, demographic and labor market characteristics, income, household composition and finances, as well as family biography.

The main dependent variable is overall life satisfaction measured on a scale of 0 (completely dissatisfied) to 10 (completely satisfied). In separate regressions, we utilize variables capturing satisfaction with different life domains such as leisure time, housework, income, standard of living, and health status, all of which are measured on a $0-10$ scale (see Table 10 in Appendix A for variable definitions). The satisfaction with housework is only asked to those respondents who are engaged in household chores.

The GSOEP includes a variable reporting all types of labor force status since the last interview, including private employment, civil service, self-employment, apprenticeship/traineeship, registered unemployment, retirement, and being in education. In addition - and importantly for our identification strategy-starting in 1985, the GSOEP introduced a question on the reasons for job termination and since 1991 the answers have included a category for "place of work closed," which allows distinguishing between voluntary and involuntary unemployment (Kassenboehmer and Haisken-DeNew 2009). We exploit this information to construct an indicator for exogenous spousal unemployment. However, since the possible answer categories in 1999 and 2000 excluded company closure, we omit these two years from our analyses.

Our analysis also utilizes the information on indirectly affected respondents' demographic and labor market characteristics such as age, education, health (number of doctor visits and disability status), marital and labor force status, working hours, as well as household characteristics such as number of children, household size, household income, home ownership, and place of residence. The year 1993 is excluded from the estimations due to the unavailability of the doctor visits variable. In separate regressions, we also include controls for the directly affected spouse's future job loss expectations and the duration of the unemployment episode due to plant closing. Table 10 in Appendix A describes the variables used in the analysis. 


\subsection{Analysis sample}

Our analysis samples comprise cohabiting couples - regardless of their formal marital status - matched based on spouse and household identifier variables observed from 1991 to 2015 , with the exception of the years 1993,1999 , and 2000 . We separately examine couples in which the husband enters unemployment from those in which the wife enters unemployment. The directly affected spouses are defined as those who potentially experience unemployment due to plant closure and are full- or part-time private employees in the previous time period (time $t-1$ ). The "private employee" category excludes pensioners, civil servants, self-employed, and those in military/community service and students. ${ }^{10}$ In the current time period (time $t$ ), directly affected spouses either continue to be private employees or become registered unemployed and experience unemployment due to company closure. ${ }^{11}$ In other words, spouses in our treated and comparison groups start from the same initial labor market condition, but in the next period we observe them, some experience joblessness due to company closures (treated group) while others remain continuously employed (comparison group). To capture the working-age population, we restrict the ages of the directly affected spouses to range between 18 and 67 , while the indirectly affected spouses can be of any age and employment status. We exclude couples in which both the husband and wife simultaneously experienced job loss due to plant closure.

Our "husband" analysis sample (where the wife potentially experiences exogenous job loss) comprises 51,816 couple-years, or 10,682 couples, among which 201 wives experience job loss due to plant closure. The "wife" sample (where the husband potentially experiences exogenous job loss) includes 62,903 couple-years, or 12,208 couples, among which 280 husbands lose their jobs due to workplace closures. Tables 11 and 12 in the Appendix furnish summary statistics.

\section{Empirical specification}

The life satisfaction $Y$ of the indirectly affected spouse $i$ observed at time period $t$ can be specified as:

$$
Y_{i t}=\alpha+\beta U^{S}{ }_{i t}+X^{\prime}{ }_{i t} \Omega+\gamma_{i}+\tau_{t}+\varepsilon_{i t}
$$

In this setup, the unit of observation is the couple-year, while $U^{S}$ is a binary indicator for spousal job loss due to workplace closure. In the "wife" sample, $U^{S}$ takes the value of 1 if the husband changes his labor force status from being a private employee to being registered unemployed due to a plant closure, and 0 if he remains in private

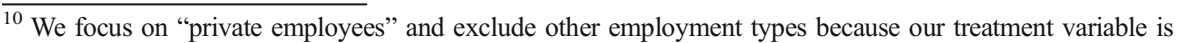
defined based on "company closures." Specifically, civil servants are unlikely to experience workplace closures and their employment status cannot be affected by the treatment. For the same reason, we exclude students but include trainees/apprentices in our definition of "private" employees. The self-employed are also omitted from the analysis sample, as they are not subject to unexpected and exogenous unemployment by nature of their job.

${ }^{11}$ Because the GSOEP is conducted once a year, the job loss due to company closure could have occurred any time between two consecutive years (i.e., time $t-1$ and time $t$ ) in which the respondent is observed.
} 
employment. Similarly, in the "husband" sample, $U^{S}$ is defined with respect to the wife's employment status. Furthermore, $X$ is a vector denoting the indirectly affected spouse's individual-level characteristics (age, age squared, years of schooling, labor force status, annual work hours, annual doctor visits, and disability status) as well as a vector of household-level controls (including the number of children, household size, home ownership, (log of) total disposable household income, indicator for west/east of Germany and federal state), $\gamma$ and $\tau$ are individual and year fixed effects, respectively, and $\varepsilon$ is the stochastic error term. Given the individual fixed effects, the subjective wellbeing consequences of spousal unemployment are identified from variation coming from couples in which one partner changes their labor force status from being a private employee to being registered unemployed due to a plant closure. Furthermore, as explained in Section 3.2, by construction, spouses are matched using the spouse and household identifier variables. Each individual is thus representative of the couple and individual fixed effects are thus also couple fixed effects. As such, the fixed effects capture selection issues associated with household formation such as assortative mating. Our specifications are therefore robust to certain types of endogeneity related to time-invariant individual- and couple-level heterogeneity that is simultaneously correlated with job loss and subjective well-being. All models are estimated separately for the indirectly affected husband's and wife's life satisfaction outcomes, and include robust standard errors, clustered at the individual (couple) level.

One objection to the specification above is that the income variable may be endogenous with spousal employment status: unemployment reduces household income, which in turn lowers life satisfaction. Ideally, we would like to control for an income source that is unaffected by spousal unemployment, although finding such an income variable is non-trivial. To understand the extent to which our results could be driven by the endogeneity of the income variable, we compare and contrast specifications that control for household income from asset flows (savings, dividends, and rents) with those that include disposable household income. While also potentially being endogenous, household income from asset flows is only indirectly related to labor income. In addition, we also offer specifications that exclude the income variable. Nevertheless, excluding income from the regressions altogether changes the interpretation of the $U^{S}$ coefficient estimate. Specifically, when we control for household income, the parameter $\beta$ represents the non-pecuniary "costs" of spousal unemployment, i.e., the well-being consequences of unemployment above and beyond income (Winkelmann and Winkelmann 1998). Given the similarity of the results with both income variables, our preferred specification is the one controlling for real disposable household income, which is conventional in the literature on subjective well-being and unemployment.

Because life satisfaction is an ordinal variable measured on $0-10$ scale, we should technically estimate Eq. (1) using an ordinal logit or probit regression. As is common in the literature, all specifications use ordinary least squares (OLS) individual fixed effects since ignoring the ordinality of the data holds little consequence for the end result (Ferrer-i-Carbonell and Frijters 2004). The fixed effects regressions and the fact that unemployment entry due to company closure is exogenous to spousal life satisfaction allow for the causal interpretation of our estimates. Nevertheless, one may be concerned about the violation of the assumption on the exogeneity of unemployment due to plant closure if employees or their spouses anticipate unemployment. We test the validity of 
this assumption by including a control variable for the (lagged) job loss expectations of the directly affected spouse. In addition, we provide a battery of sensitivity checks such as controlling for attrition and couple dissolution, accounting for the duration of the current unemployment episode, controlling for state-specific macroeconomic shocks, regional-level unemployment shocks, weighting, and using voluntary unemployment entry. We also show specifications using unemployment due to dismissals, which is another source of involuntary job loss but is less exogenous than plant closures.

Finally, we explore the extent to which our results are driven by income considerations and provide novel results regarding the anticipation of and adaptation to spousal unemployment following a method used in Clark and Georgellis (2013) and Qari (2014). Specifically, we model anticipation and adaptation as:

$$
\begin{aligned}
Y_{i t}= & \alpha+\beta_{-3} U_{-3, i t}^{S}+\beta_{-2} U_{-2, i t}^{S}+\beta_{-1} U^{S}{ }_{-1, i t}+\beta_{0} U_{0, i t}^{S}+\beta_{1} U_{1, i t}^{S}+\beta_{2} U_{2, i t}^{S} \\
& +X^{\prime}{ }_{i t} \Omega+\gamma_{i}+\tau_{t}+\varepsilon_{i t}
\end{aligned}
$$

where the life satisfaction $(Y)$ of the indirectly affected spouse, the vector of covariates $(X)$, and $\gamma$ and $\tau$ are individual and year fixed effects, respectively, as in Eq. (1). Importantly, Eq. (2) estimates the anticipation and adaptation effects based on the treated sample, i.e., all couples who will eventually experience unemployment due to plant clsoings. ${ }^{12}$ To capture the anticipation of spousal unemployment, we introduce the leads of the plant closing indicator in Eq. (2). The three dummies $U_{-1}^{S}, U^{S}$, and $U^{S}-3$ refer to future entry into unemployment and are coded as 1 if the respondent's spouse will enter unemployment due to plant closure in the next 1-2 years, 2-3 years, and 3 years or more, respectively and 0 otherwise. Similarly, $U_{0}^{S}$ denotes the entry to unemployment due to plant closure in the first year of unemployment. To capture the adaptation to spousal unemployment, we introduce the lags of the plant closing indicator in Eq. (2). The two dummy variables $U^{S}{ }_{1}$ and $U^{S}{ }_{2}$ take the value of 1 if the respondent has been unemployed due to plant closure for 1-2 years and more than 2 years, respectively, and 0 otherwise. $U^{S}$ is the reference category in the estimation of Eq. (2). Given that all unemployment dummies are mutually exclusive, any individual is only present in one of the six categories at any given year. As we estimate (2) using fixed effects models, the comparison is within-individual and with respect to the omitted category $U_{-3}^{S}$. Thus, for example, the coefficient estimate of $U^{S}{ }_{1}$ should be interpreted as the change in the well-being of indirectly affected spouses whose partners have been unemployed for 1-2 years compared to the life satisfaction scores of the same individuals 3 (or more) years before their partners enter unemployment. Similarly, the coefficient estimate on the lead variable $U^{S}$ is interpreted as the life satisfaction response of the spouse whose partner will lose her/his job due to plant closure in the next 1 to 2 years.

\footnotetext{
${ }^{12}$ In fact, these are the observations that generate the variation used in the estimatin in Equation (1) (i.e., 201 treated wives and 280 treated husbands).
} 


\section{Main results}

Table 1 presents the well-being consequences of involuntary spousal unemployment due to company closures for the indirectly affected spouses. ${ }^{13}$ All regressions include individual (i.e., couple) fixed effects and controls for the year of survey and state of residence. The left panel of the table (columns (1)-(3)) reports the results for men whose (female) partners experience plant closures. Similarly, the right panel (columns (4)-(6)) reports the women's life satisfaction response to their (male) partners' job loss. Models (1) and (4) do not control for income, Models (2) and (5) include a variable for (the log of) real household income from asset flows, while Models (3) and (6) control for (the log of) real disposable household income. In subsequent regressions, we only show the results controlling for disposable household income.

The estimates presented in Table 1 unequivocally demonstrate that regardless of gender, spousal job loss due to company closure negatively influences the life satisfaction of the indirectly affected partner. Men's life satisfaction declines by about 0.34 points as a result of their wives' unemployment. The effect is slightly less pronounced among women whose spouses become jobless, amounting to a reduction in perceived well-being by about 0.25 points. However, the gender difference is not statistically significant. ${ }^{14}$

These coefficient estimates differ from those in Winkelmann and Winkelmann (1995), who find that - controlling for one's own and one's partner's employment status - indirectly affected wives experience a 0.5 -point drop in life satisfaction, while the coefficient estimate for males whose wives become jobless is positive and statistically insignificant. The divergence of our results from Winkelmann and Winkelmann (1995) could be due to the different sample selection and analysis period. More importantly, unlike in Winkelmann and Winkelmann (1995), our estimates are based on an exogenous unemployment entry. Comparing the coefficient estimates for indirectly affected women that we find $(0.25)$ with those in Winkelmann and Winkelmann (0.5) implies an upward bias when selection is not taken into account.

\footnotetext{
${ }^{13}$ Regressions for the sample of married and cohabiting couples showing the effects of own unemployment on one's own life satisfaction are shown in Table 14 in Appendix B. Columns (1)-(3) of Table 14 present the results for men (who themselves become unemployed due to plant closure), while columns (4)-(6) demonstrate the findings for women (who themselves become unemployed due to company closure). The main takeaway from this table is that men's negative well-being response to own unemployment is slightly stronger than that for females. Based on our preferred specification controlling for household income, job loss reduces men's life evaluations by 0.98 points, while the corresponding drop for women is roughly similar in magnitude, at about 0.84 points. Our results are not directly comparable to those in Kassenboehmer and Haisken-De New (2009) as we have a matched-couple sample, the sample restriction that individuals are private employees in the year prior to unemployment, and we use different years for the estimation. Kassenboehmer and Haisken-De New (2009) essentially show that after controlling for unemployment, there are no effects of being unemployed due to company closings for men but there are large effects for women. ${ }^{14}$ In Table 15 in Appendix B, we test whether there is a gender difference in the estimated effects presented in Table 1. Specifically, combining the husband and wife analyses samples into a single dataset, we run a regression interacting the gender of the indirectly affected spouse with spousal unemployment. In Table 15, the coefficient estimate for the job loss variable $(-0.35)$ corresponds to husbands' life satisfaction reactions when their wives become unemployed and is a direct parallel to the finding in Table 1, column (3). The coefficient estimate for women whose husbands become jobless is given by summing up the coefficients for job loss and that for the interaction variable (job loss $\times$ female) and corresponds to the finding in Table 1, column (6). The slight difference in the coefficient estimates is due to the fact that we have couple fixed effects in Table 1 and household fixed effects in Table 15. The interaction term is statistically insignificant, suggesting that there is no difference between the life satisfaction responses between spouses of both genders. Put simply, husbands and wives care just as much when their spouse involuntarily loses their job.
} 


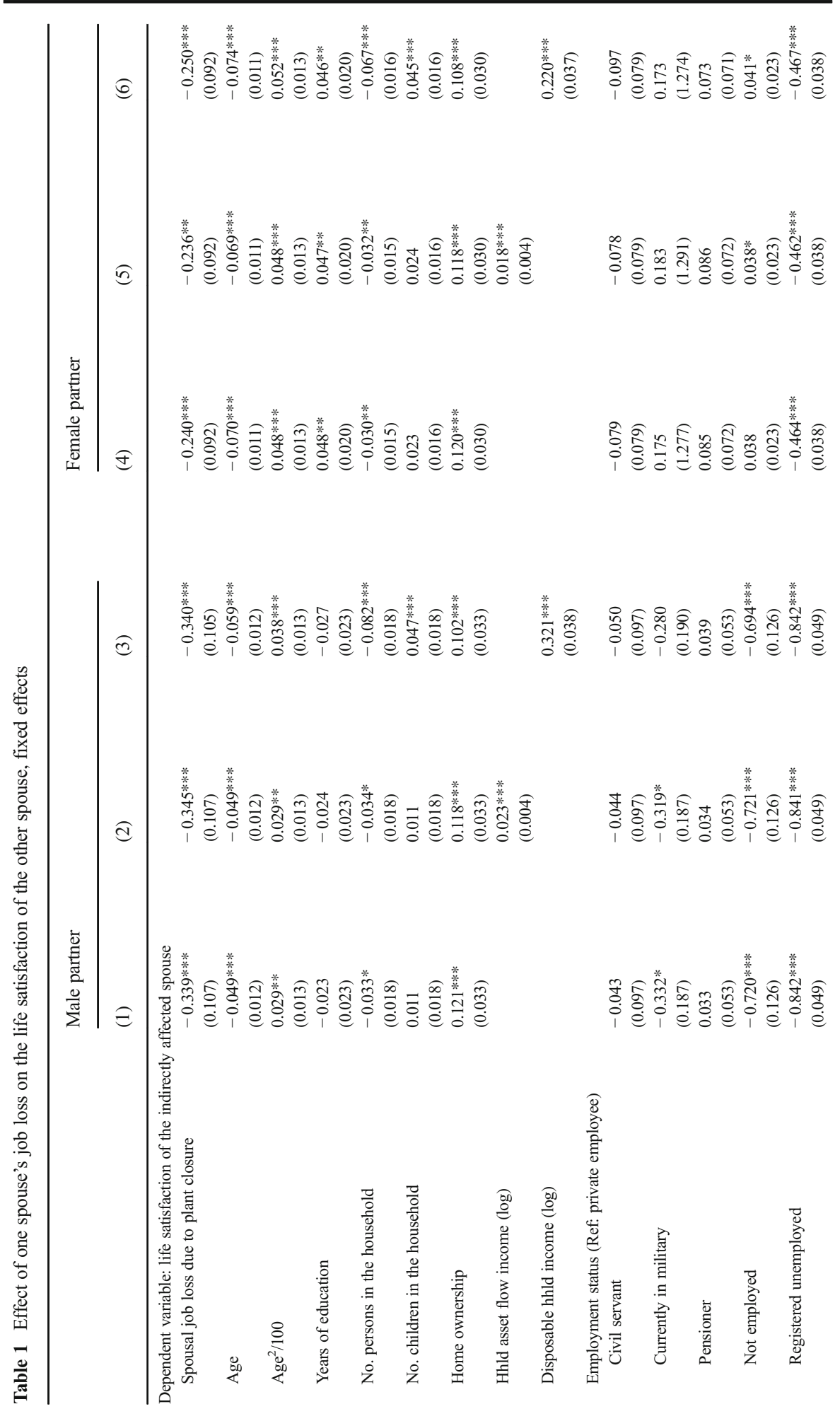




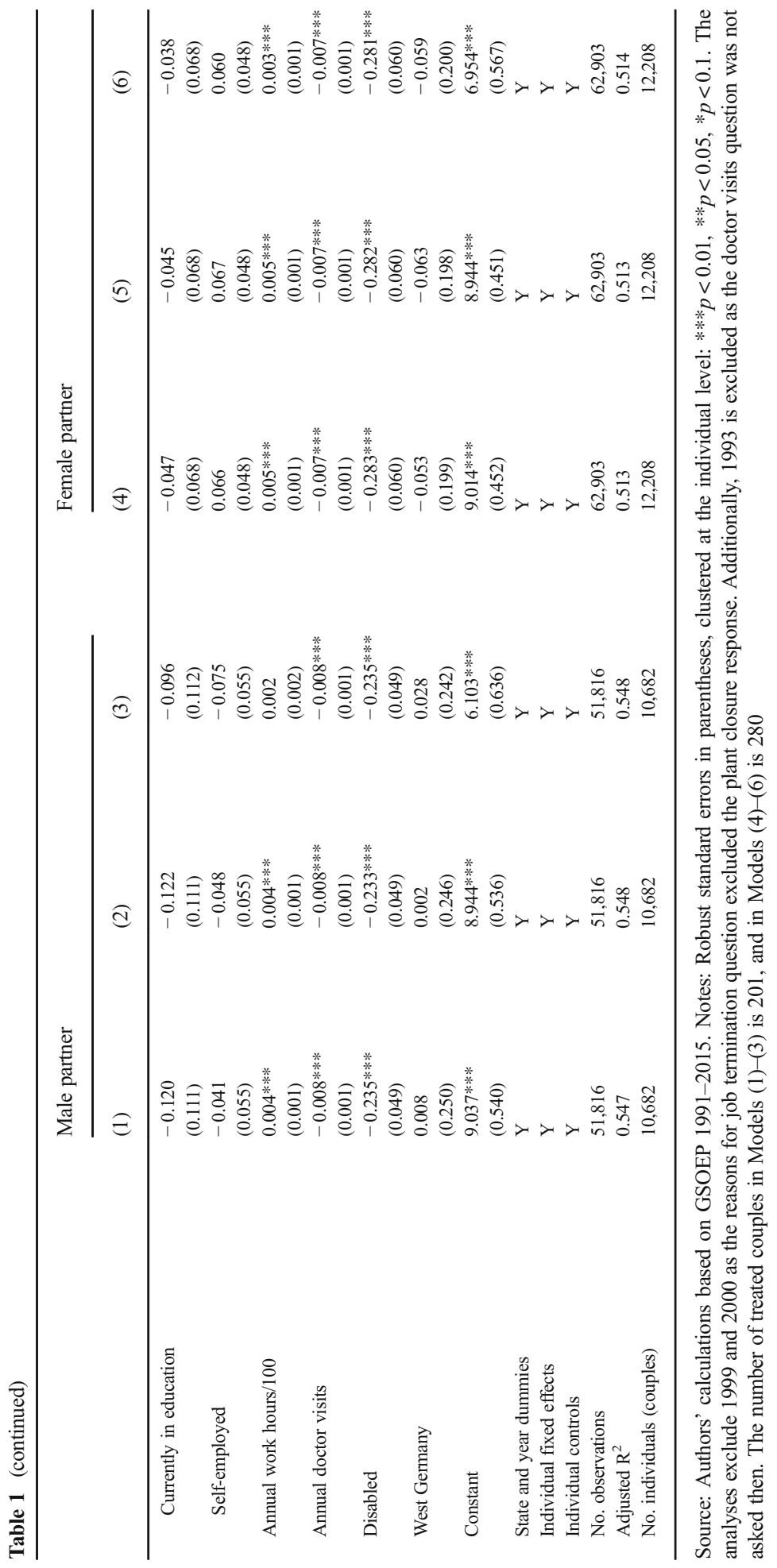


Furthermore, the results remain unchanged when excluding income and controlling for household income from asset flows, which suggests that our results capture the nonpecuniary costs of spousal unemployment. Benchmarked against the coefficient estimates of one's own unemployment due to firm closure for the couple sample (Table 14 in Appendix B), our results represent about one third to one quarter of the life satisfaction effects of one's own unemployment.

Another way to quantify how much spouses care about their partners' job loss is to utilize the life satisfaction valuation approach. Specifically, we calculate the amount of household income required to compensate the indirectly affected spouse for the life satisfaction penalty resulting from their partner's job loss. Based on the sample mean of real household income of 46,000 Euro, male partners need to be given about 49,300 Euro. For indirectly affected women, the corresponding compensation is about 52,000 Euro. ${ }^{15}$ The findings thus far indicate that the costs of unemployment are non-monetary and large and are also borne by indirectly affected spouses.

The coefficient estimates of the control variables in Table 1 are generally in line with the economic theory and previous studies. For instance, a higher educational attainment is positively correlated with the indirectly affected spouse's own life satisfaction. Likewise, home ownership — which is a proxy for wealth — and household income are positively associated with spousal life satisfaction. Like other studies using the GSOEP (Frijters and Beatton 2012; Kassenboehmer and Haisken-DeNew 2012), we fail to document a $U$-shaped relationship between life satisfaction and age in fixed effects estimations (see Ulloa et al. 2013 for a review). Finally, disability status and the annual doctor visits - both of which are proxies for health status - are negatively associated with life satisfaction. In addition, while the magnitudes of the coefficient estimates for the control variables are generally the same across genders, those for one's own unemployment have a substantially larger negative effect on men compared with women (based on the coefficient estimate for registered unemployed).

\section{Robustness checks}

In this section, we explore whether our results are robust to a battery of sensitivity tests. Our first check concerns the exogeneity of the company closure variable. Like Kassenboehmer and Haisken-DeNew (2009), we argue that plant closures are exogenous from the perspective of the individual respondent or their spouse. Nevertheless, one concern might be that employees who remain at the firm until the very end may have had reasons for doing so despite knowing about the looming closure. As Kassenboehmer and Haisken-DeNew (2009) point out, if a company takes a few

\footnotetext{
${ }^{15}$ Following the conventional life satisfaction valuation approach (Clark \& Oswald 2002), we calculated the compensations by dividing the coefficient estimates for spousal unemployment by the household income coefficient and then multiplying by the sample average of household income. For male partners, based on the coefficient estimate in Table 1, the corresponding valuation is given by dividing the job loss coefficient of 0.340 by the income coefficient of 0.321 and then multiplying by the average household income in the sample of about 46,000 Euros (reported in Table 11). The compensating valuation for female partners is calculated in the same way. An alternative quantification method proposed by Knabe and Rätzel (2011a) takes into account intertemporal spillovers of temporary income compensations. According to this approach, the monetary compensation we calculated based on the standard approach should be interpreted as an upper bound.
} 
months or years to shut down, then only the least flexible employees would remain until the end, thus implying that the estimated effects represent an upper bound of the actual average effect of spousal unemployment on life satisfaction. To ensure that the plant closure experience was indeed exogenous, Table 2 furnishes results controlling for the lagged directly affected spouse's unemployment expectations (see Table 10 in Appendix A for variable definitions). In separate specifications (columns (2) and (4)), we also code all missing values for this variable as "no response" and include them in the regressions. This coding helps to avoid losing observations when we construct the

Table 2 Effect of one spouse's job loss on the life satisfaction of the other spouse, with a control for job loss expectation, fixed effects

Male partner

(1)
Dependent variable: life satisfaction of the indirectly affected spouse

Spousal job loss due to plant closure

$$
-0.391 * *
$$

(0.156)

Lag of job loss expectation (Ref: unlikely)

Not probable

$$
-0.086^{* * * *}
$$

Probable

$$
-0.141 * * *
$$

Certain

$$
-0.182 *
$$

(0.093)
Female partner

(3)
(2)

(4)

$\begin{array}{lll}-0.315^{* * *} * & -0.423 * * * & -0.234 * * \\ (0.107) & (0.157) & (0.092)\end{array}$

\begin{tabular}{|c|c|c|c|c|}
\hline \multicolumn{5}{|c|}{ Lag of job loss expectation (Ref: missing) } \\
\hline \multirow{2}{*}{\multicolumn{2}{|c|}{ Unlikely }} & \multicolumn{2}{|l|}{$0.137 * * *$} & $0.218^{* * *}$ \\
\hline & & \multicolumn{2}{|l|}{$(0.046)$} & $(0.040)$ \\
\hline \multirow{2}{*}{\multicolumn{2}{|c|}{ Not probable }} & \multicolumn{2}{|l|}{0.074} & $0.188^{* * *}$ \\
\hline & & \multicolumn{2}{|l|}{$(0.045)$} & $(0.039)$ \\
\hline \multirow{2}{*}{\multicolumn{2}{|c|}{ Probable }} & \multicolumn{2}{|l|}{0.003} & $0.115^{* *}$ \\
\hline & & \multicolumn{2}{|l|}{$(0.057)$} & $(0.051)$ \\
\hline \multirow[t]{2}{*}{ Certain } & & \multicolumn{2}{|l|}{-0.006} & -0.032 \\
\hline & & \multicolumn{2}{|l|}{$(0.088)$} & $(0.083)$ \\
\hline State and year dummies & $\mathrm{Y}$ & $\mathrm{Y}$ & $\mathrm{Y}$ & $\mathrm{Y}$ \\
\hline Individual fixed effects & $\mathrm{Y}$ & $\mathrm{Y}$ & $\mathrm{Y}$ & $\mathrm{Y}$ \\
\hline Individual controls & $\mathrm{Y}$ & $\mathrm{Y}$ & $\mathrm{Y}$ & $\mathrm{Y}$ \\
\hline No. observations & 20,950 & 51,816 & 24,949 & 62,903 \\
\hline Adjusted $\mathrm{R}^{2}$ & 0.535 & 0.549 & 0.509 & 0.514 \\
\hline No. individuals (couples) & 7279 & 10,682 & 8103 & 12,208 \\
\hline
\end{tabular}

$-0.315 * * *$

(0.157)

(0.092)
$-0.035$

(0.026)

$-0.082 *$

(0.046)

$-0.227 * * *$

(0.087)

ag of job loss expectation (Ref: missing)

Unlikely

$0.137 * *$

$(0.040)$

$0.188 * * *$

$0.115^{* *}$

$(0.051)$

$0.083)$

State and year dummies

Y

$\mathrm{Y}$

$\mathrm{Y}$

Individual fixed effects

$Y$

Source: Authors' calculations based on GSOEP 1991-2015. Notes: Robust standard errors in parentheses, clustered at the individual level: $* * * p<0.01$, $* * p<0.05, * p<0.1$. The job loss expectation variable refers to the directly affected spouse's job loss expectation in the next 2 years. In all regressions, this variable is lagged by one time period. Because the job expectation variable was not asked in all years, to prevent non-random attrition bias due to non-response, columns (3) and (4) include an indicator for missing values. The analyses exclude 1999 and 2000 as the reasons for job termination question excluded the plant closure response. Additionally, 1993 is excluded as the doctor visits question was not asked then 
lagged variable of job loss expectation and because this question was asked every other year. Specifically, the sample size declines by more than half for the husband sample and about two thirds in the wife sample (columns (1) and (3)), which explains the slightly higher coefficient estimates that the spousal job loss variable attracts in these regressions. Nevertheless, the coefficient estimates of the key regressor reported in Table 2 ((columns (2) and (4)) are substantively similar to those in Table 1, suggesting that the plant closing variable can be treated as exogenous.

Second, given the panel structure of our data, attrition - or the non-random exit of spouses from the dataset for reasons correlated with the unemployment episode- is a potential concern. To understand whether it biases the estimates, following Wooldridge's (2002) approach we constructed a binary indicator taking the value of one if the indirectly affected spouse disappears from the sample in the next time period and zero if he/she stays in the panel. In Table 3, Models (1) and (3), we show that controlling for sample attrition does not influence the results. The interaction term between the attrition dummy and the spousal job loss variable is also statistically insignificant for both genders, thus demonstrating that the cross-partner spillovers that we identify are not disproportionally higher or lower for survey dropouts. ${ }^{16,17}$

A related issue arises from the fact that partners may drop from the sample due to divorce or separation, which could be partly induced by the job loss episode (Doiron and Mendolia 2012; Eliason 2012; Hansen 2005; Rege et al. 2007). By construction, our sample comprises cohabiting couples, which may be a self-selected sample of all couples experiencing unemployment. Given that the plant closing episode happened at any time since the past interview, our partner sample may represent those with strong marriage ties or other unobserved reasons to remain together. We test whether partnership dissolution through divorce and separation following the unemployment episode influences the results. Specifically, exploiting the panel structure of the data, for the couples for which we have marital status information in the next time period, we created a binary indicator variable that is equal to one if the indirectly affected spouse separates or divorces from their current partner in the subsequent observation period. The findings reported in Table 3, columns (2) and (4), indicate that the main effect of spousal unemployment remains robust to this check. In addition, being divorced or separated in the next time period and the interaction term between divorce and spousal job loss is statistically insignificant for both the husband and wife sub-samples. This suggests that divorce among couples experiencing unemployment does not bias the

\footnotetext{
${ }^{16}$ In Table 13, we also furnish information about how the treated and comparison groups differ based on attrition status. Specifically, in panel A of Table 13, we compare the control groups based on attrition status, separately for the husband (top left panel) and wife samples (top right panel). In both the husband and wife samples, the comparison groups differ along their observable characteristics according to attrition status. Yet, importantly, the treated samples, which provide the identifying variation in our estimations, are largely unaffected by attrition. This is evidenced by the statistically insignificant differences in means for (most of) the observable characteristics in between the observations remaining and dropping in from the treated sample (Panel B).

${ }^{17}$ In addition, in Appendix Table 17, we also show the main regressions applying the sample weight, which partially addresses the concern that sample selectivity and the changing willingness to participate in surveys could be driving our results. However, note that the number of observations in Table 17 is smaller than in Table 1 as some individuals are assigned zero weights (Haisken-DeNew and Frick 2005). The coefficient estimates on spousal unemployment in Table 17 are slightly higher $(0.38$ in the husband sample and 0.3 in the wife sample), but generally similar to those presented in Table 1 ( 0.34 in the husband sample and 0.25 in the wife sample), suggesting that sample selectivity is not driving our results.
} 


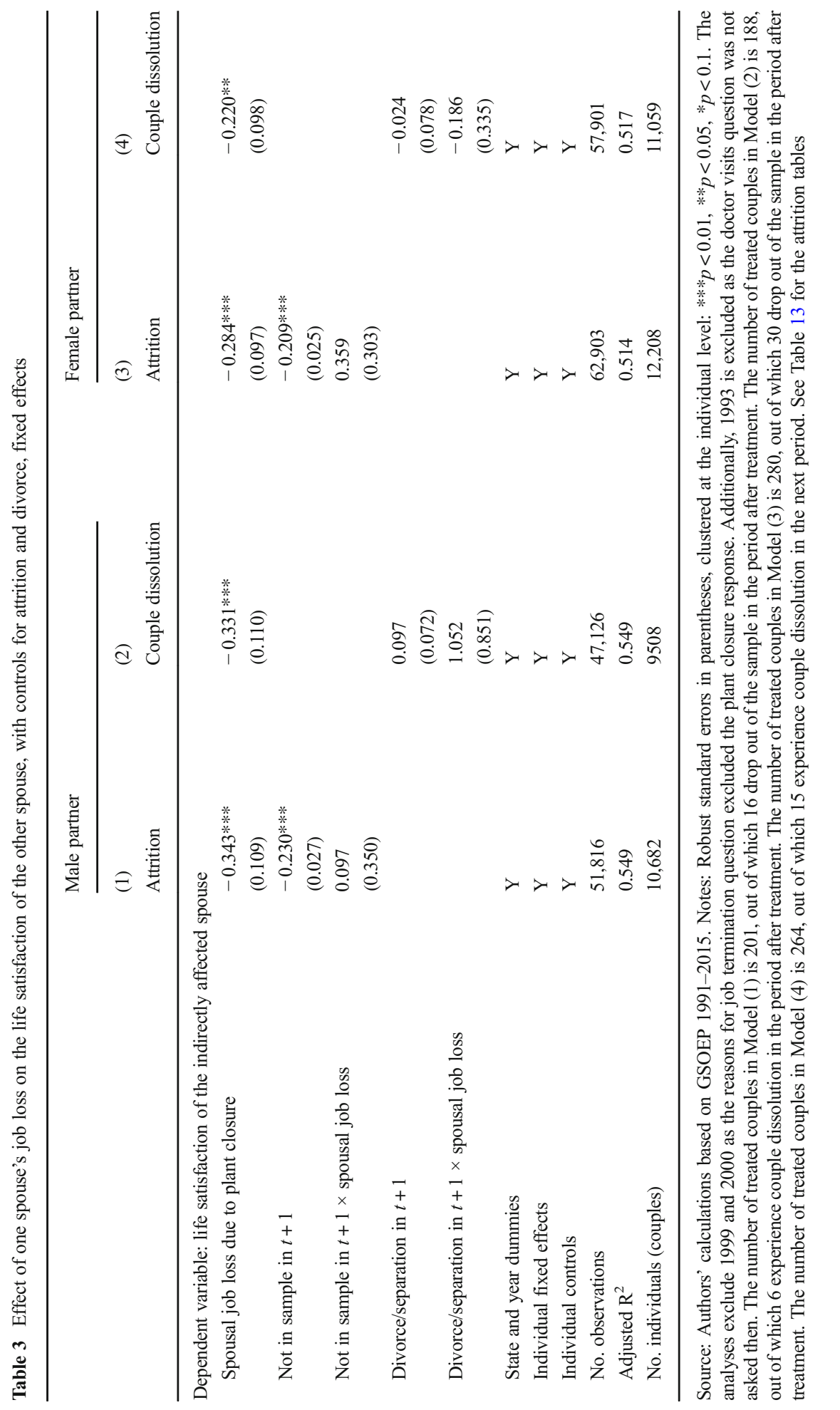


results. Yet, these results should be interpreted with caution as only 6 out of 188 treated couples experience subsequent separation in column (2) and only 15 out of 264 couples do so in column (4). ${ }^{18}$

A third identification threat may arise if plant closures are the result of certain regional shocks that also simultaneously influence life satisfaction. For example, firm closures may be driven by an overall decline in the regional economy and affect individual life satisfaction, which would upwardly bias our results. To understand the extent to which such region-specific changes matter, we conducted the analyses by including additional year $\times$ federal state interaction terms. Table 4 shows that the results in this specification remain very similar to the main results presented in Table 1, although the coefficient estimates for the spousal unemployment variable are slightly lower compared to those in the main specification in the male sample. ${ }^{19}$ In summary, Tables 2, 3, and 4 imply that the finding that unexpected and involuntary spousal unemployment leads to cross-spouse life satisfaction declines is robust across different specifications and sensitivity tests. ${ }^{20,21}$

\section{Channels and explanations}

\subsection{The income channel revisited}

Our results thus far suggest that the cross-spouse declines in life satisfaction associated with partner unemployment are largely independent of current income. However, it is possible that the psychological costs of unemployment borne by indirectly affected spouses are due to financial concerns about the future. As Chadi and Hetschko (2017) note, income losses resulting from unemployment may be unimportant for subjective

\footnotetext{
${ }^{18}$ We lack information on marital status in the next time period for some couples. In separate specifications, following Mendolia (2014), we also created a dummy variable for partner change (instead of divorce), but the results (available upon request) were not very telling due to the small number of indirectly affected spouses who change their partner and experienced job loss due to plant closure.

${ }^{19}$ Ideally, we would have wanted to check whether local-level shocks influence the results. Indeed, we merged the GSOEP data with regional-level (Raumordnungs-Regionen (ROR)) data from the INKAR database. However, we do not have sufficient degrees of freedom to credibly identify these effects. We offer analyses controlling for ROR-level unemployment in Table 16 in the appendix. All regressions are for 1998, 2001-2014 due to the INKAR data availability.

${ }^{20} \mathrm{We}$ also considered whether the results are driven by couples who experience multiple plant closure episodes. In the "husband" sample, whereby the wife loses her job, among the 201 "treated" cases, 193 wives (96.02\%) lose their job just once, while 8 (3.98\%) lose their job two times. In addition, in the "wife" sample, whereby the husband loses his job, out of the 280 treated cases, $268(95.71 \%)$ experience unique job losses due to plant closures, while 12 couples experience two job losses due to plant closure. Therefore, it does not appear that the results are driven by couples who keep on experiencing plant closings on multiple occasions. Furthermore, to rule out the possibility that the results are further driven by couples in which the directly affected spouse has long unemployment experiences (due to various reasons), we further control for the directly affected spouse's cumulative unemployment experience to date and also interact this variable with the treatment. The results remain unchanged, which adds another level of reassurance about their robustness (results available upon request).

${ }^{21}$ In Table 19, we present some suggestive evidence that the negative well-being costs borne by the wives of the unemployed may be disproportionately concentrated among those with children in the household. The same does not hold true among indirectly affected husbands. We also note that Model (2) in Table 19 should be interpreted with caution as the standard errors in this specification are very large.
} 
Table 4 Effect of one spouse's job loss on the life satisfaction of the other spouse, controlling for statespecific shocks, fixed effects

Male partner

(1)

\begin{tabular}{lll}
\hline Dependent variable: life satisfaction of the indirectly affected spouse & \\
Spousal job loss due to plant closure & $-0.288^{* * *}$ & $-0.249^{* * *}$ \\
& $(0.104)$ & $(0.092)$ \\
State and year dummies & $\mathrm{Y}$ & $\mathrm{Y}$ \\
State $\times$ year dummies & $\mathrm{Y}$ & $\mathrm{Y}$ \\
Individual fixed effects & $\mathrm{Y}$ & $\mathrm{Y}$ \\
Individual controls & $\mathrm{Y}$ & $\mathrm{Y}$ \\
No. observations & 51,816 & 62,903 \\
Adjusted $\mathrm{R}^{2}$ & 0.550 & 0.515 \\
No. individuals (couples) & 10,682 & 12,208
\end{tabular}

Female partner

(2)

Source: Authors' calculations based on GSOEP 1991-2015. Notes: Robust standard errors in parentheses, clustered at the individual level: $* * * p<0.01, * * p<0.05,{ }^{*} p<0.1$. The analyses exclude 1999 and 2000 as the reasons for job termination question excluded the plant closure response. Additionally, 1993 is excluded as the doctor visits question was not asked then

well-being as the unemployed substitute their former labor income with the income of other household members and unemployment benefits. Furthermore, Germany provides a relatively substantial unemployment insurance package in the first year of unemployment, which may mitigate the associated labor income loss. However, as the unemployment duration increases, the unemployment benefits, the re-employment probability, and household income decrease. Thus, the well-being loss resulting from spousal unemployment may reflect concerns about the directly affected partner's future labor market prospects and earnings rather than worries about the current situation.

To understand the extent to which such concerns about the future influence our results, in Table 5 we control for the duration (in months) of the spouse's current unemployment episode (Models (1) and (3)) and household income in the next survey period (Models (2) and (4)). ${ }^{22}$ The duration of the unemployment episode of the partner is a count variable coded as 0 if the respondent's spouse is currently employed. The main results and conclusions remain virtually unaltered. The coefficient estimates for the duration of the current unemployment episode is relatively small in magnitude and statistically insignificant. Furthermore, Models (2) and (4) show that while future household income-which captures financial concerns about the future-is positively associated with current life satisfaction, controlling for it does not seem to eliminate the magnitude of the spousal job loss coefficient, thus suggesting that the results are not driven by considerations about future re-employment or finances.

\footnotetext{
${ }^{22}$ To rule out the possibility that the results are further driven by couples in which the directly affected spouse has long unemployment experiences (due to various reasons), we further control for the directly affected spouse's cumulative unemployment experience to date and also interact this variable with the treatment. The results remain unchanged, which adds another level of reassurance about their robustness (results available upon request).
} 
Table 5 Effect of one spouse's job loss on the life satisfaction of the other spouse, controls for unemployment duration and future household income, fixed effects

\begin{tabular}{|c|c|c|c|c|}
\hline & \multicolumn{2}{|c|}{ Male partner } & \multicolumn{2}{|c|}{ Female partner } \\
\hline & (1) & (2) & (3) & (4) \\
\hline \multicolumn{5}{|c|}{ Dependent variable: Satisfaction of the indirectly affected spouse } \\
\hline Spousal job loss due to plant closure & $\begin{array}{l}-0.424 * * \\
(0.191)\end{array}$ & $\begin{array}{l}-0.362 * * * \\
(0.107)\end{array}$ & $\begin{array}{l}-0.335^{* *} \\
(0.140)\end{array}$ & $\begin{array}{l}-0.238^{* *} \\
(0.097)\end{array}$ \\
\hline Duration of spouse's unemployment spell & $\begin{array}{l}0.179 \\
(0.311)\end{array}$ & & $\begin{array}{l}0.176 \\
(0.225)\end{array}$ & \\
\hline Disposable hhld income $(\log )$ in $t+1$ & & $\begin{array}{l}0.273 * * * \\
(0.042)\end{array}$ & & $\begin{array}{l}0.127 * * * \\
(0.031)\end{array}$ \\
\hline State and year dummies & $\mathrm{Y}$ & $\mathrm{Y}$ & $\mathrm{Y}$ & Y \\
\hline Individual fixed effects & $\mathrm{Y}$ & $\mathrm{Y}$ & $\mathrm{Y}$ & $\mathrm{Y}$ \\
\hline Individual controls & $\mathrm{Y}$ & $\mathrm{Y}$ & $\mathrm{Y}$ & Y \\
\hline No. observations & 51,707 & 45,004 & 62,704 & 54,918 \\
\hline Adjusted $\mathrm{R}^{2}$ & 0.549 & 0.550 & 0.513 & 0.608 \\
\hline No. individuals (couples) & 10,632 & 9251 & 12,124 & 10,796 \\
\hline
\end{tabular}

Source: Authors' calculations based on GSOEP 1991-2015. Notes: Robust standard errors in parentheses, clustered at the individual level: $* * * p<0.01,{ }^{* *} p<0.05,{ }^{*} p<0.1$. The analyses exclude 1999 and 2000 as the reasons for job termination question excluded the plant closure response. Additionally, 1993 is excluded as the doctor visits question was not asked then. The $\mathrm{N}$ of treated couples in Model (1) is 201, in Model (2) is 190; in Model (3) is 279 and in (6) is 256

In Table 6, we further explore whether the results depend on who the couple's primary earner is. ${ }^{23}$ The intuition is that spousal unemployment may not be as detrimental for the indirectly affected spouse if the unemployed partner was not the primary "breadwinner" in the couple. Nonetheless, the results in columns (1) and (6) demonstrate that the primary earner variable and its interaction with spousal job loss indicator are statistically insignificant, suggesting that the main results are independent of this factor.

Next, we explore the extent to which the main effects that we identify differ for couples at the bottom and top of the household income distribution. For this purpose, in separate regressions, we interact an indicator variable for bottom, middle, and top quartile earners with the job loss variable. The results presented in columns (2)-(5) of Table 6, respectively, demonstrate that there are no differential effects at any quartile of the earnings distribution for indirectly affected husbands. In other words, spousal job loss equally hits indirectly affected spouses coming from both relatively poor and relatively rich households. The interaction term of the top income quartile is negatively and marginally statistically significant for indirectly affected wives (column (10)), implying that women in relatively well-off households may be disproportionately

\footnotetext{
${ }^{23}$ We define the primary earner as the partner earning at least 500 Euros more per year than his/her spouse. We perform similar exercises using wider earning gaps between spouses, up to 2000 Euros per year. The results are robust to the usage of different thresholds to define the primary earner.
} 


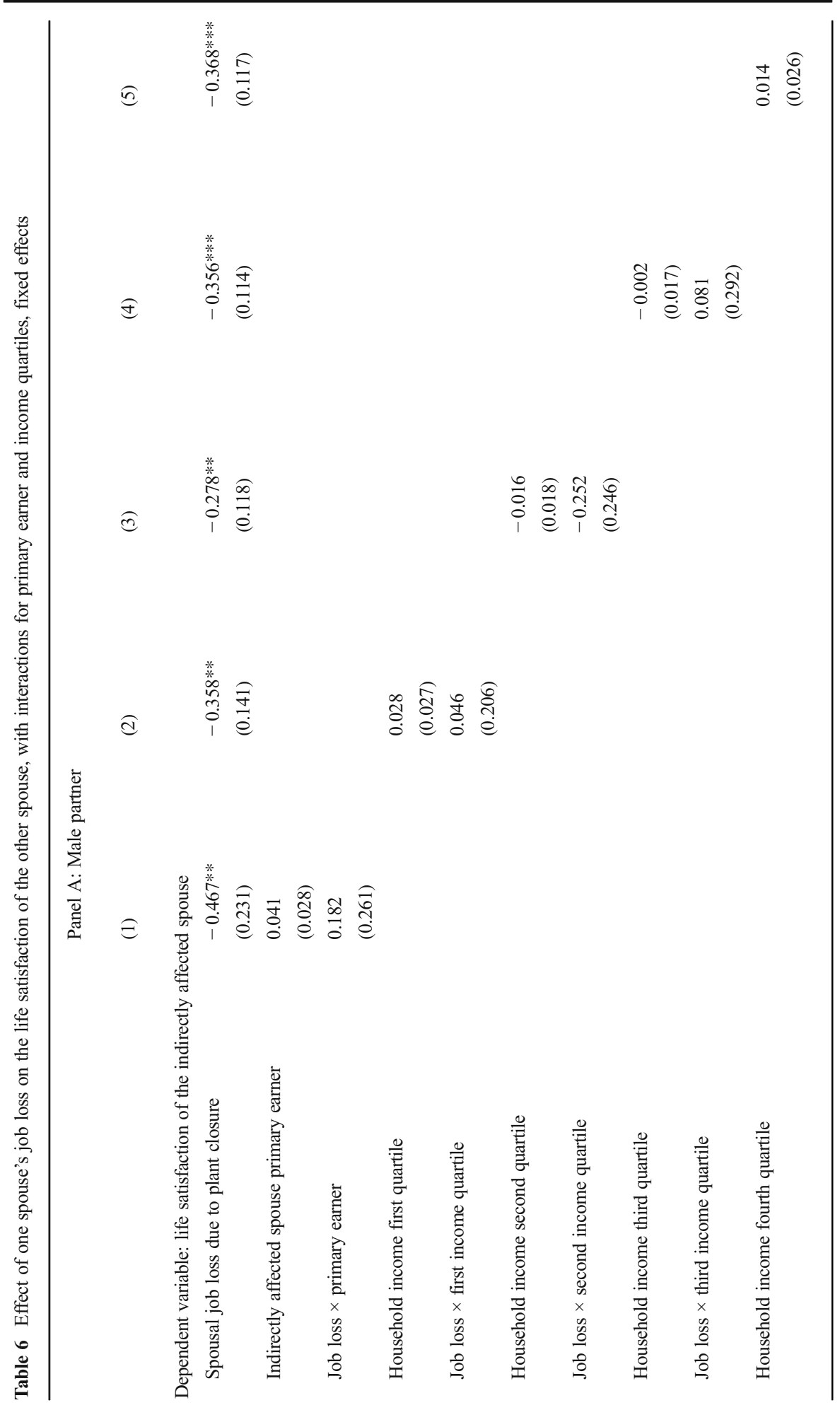




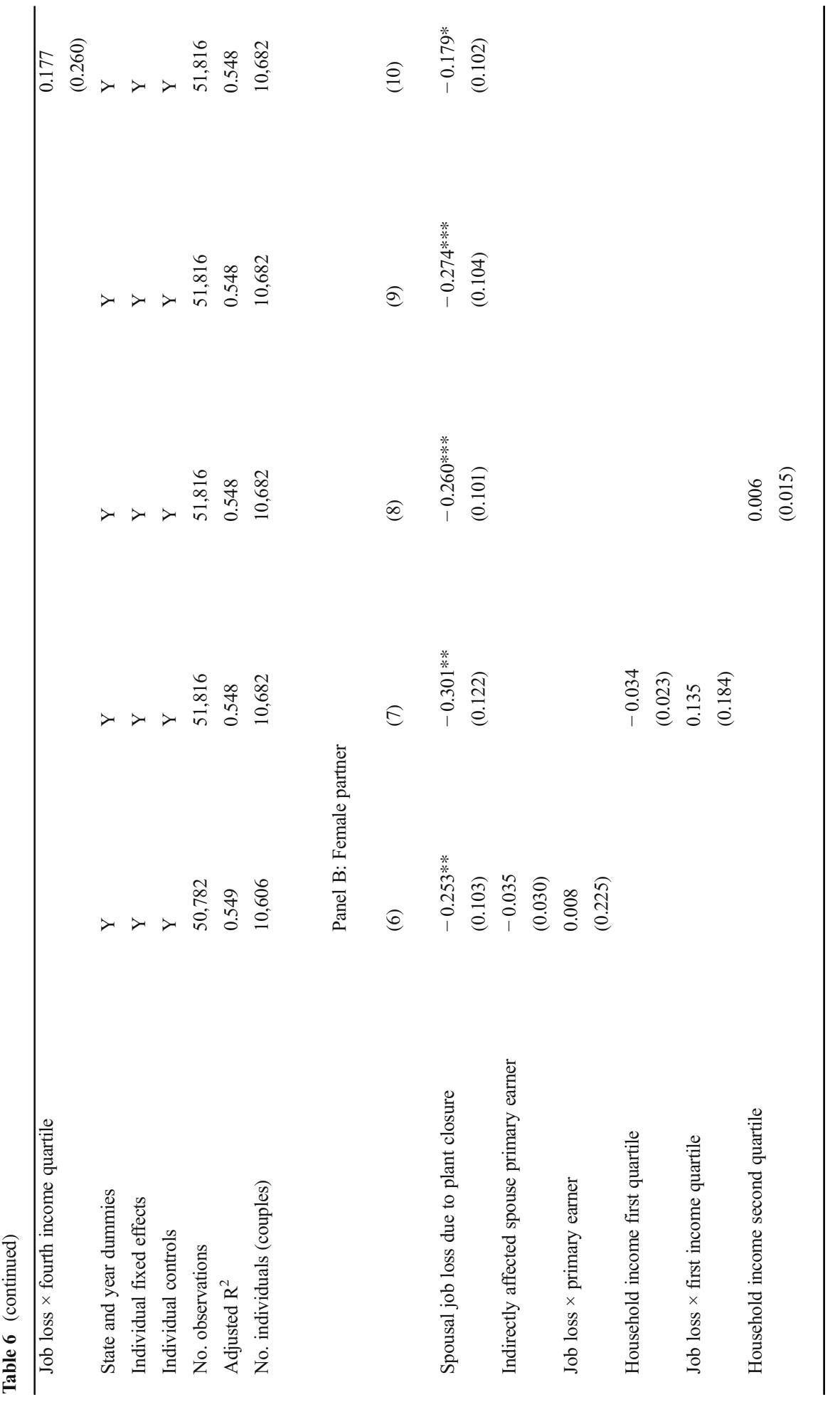


g
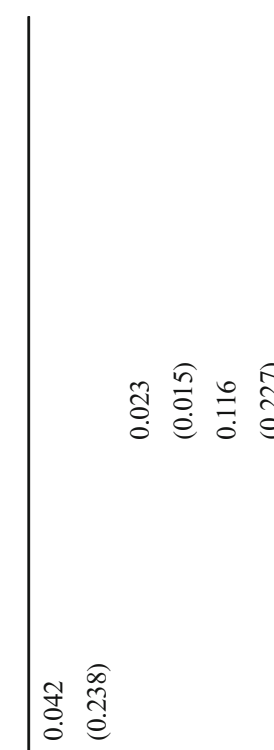

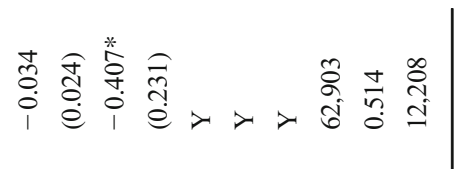

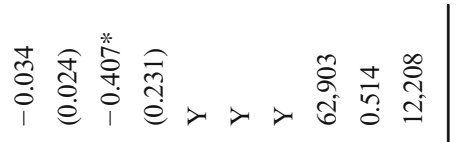

‥

क्ष

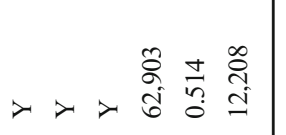


negatively affected by their partner's joblessness. This result may be driven by the stronger social norm to be successful among higher-status households. ${ }^{24}$

The results presented in this section imply that the life satisfaction penalty from involuntary spousal unemployment is generally not due to pecuniary factors; rather, it likely reflects the psychological distress and other non-pecuniary costs of unemployment such as social stigma. ${ }^{25}$

\subsection{Is there a social norm of unemployment at the couple level?}

Following Clark (2003), we test whether there is a social norm of unemployment within the couple, i.e., whether one's own unemployment mitigates the negative well-being consequences of spousal job loss due to plant closure. Using a cross-section of respondents from Berlin and Magdeburg in 2008, Knabe et al. (2016) examine how one's own unemployment depends on the labor force status of the partner. The authors find that the large well-being gap between unemployed and employed partnered men (4.3 points on a $0-10$ scale) is mitigated if their spouses are unemployed or inactive. Among partnered women, one's own unemployment is associated with a 1.1 point decline in life satisfaction, which is partially mitigated by having an inactive partner. However, our results do not support the evidence of a social norm of unemployment at the couple level. The results in Table 7 document that while personal unemployment is negatively associated with life satisfaction, the interaction term is statistically insignificant, suggesting that one's own unemployment has no additional effect above and beyond the negative impact of spousal job loss due to company closure. Nonetheless, one should be cautious in interpreting these results given the lack of sufficient statistical power to identify the effects.

\subsection{Satisfaction with life domains}

In Table 8, we further explore whether and how spousal unemployment affects satisfaction with housework, free time, household income, living standards, and health. While Chadi and Hetschko (2017) study satisfaction with different life domains resulting from individual unemployment, to our knowledge no comparable analyses

\footnotetext{
${ }^{24}$ In Table 20, we offer the results from a similar exercise whereby we interact the quartiles of household income from asset flows with the treatment variables. The intuition is that couples with large asset incomes may not be as affected by spousal unemployment compared to a couple with relatively small assets. We see some suggestive evidence for this hypothesis in Model (8) whereby the life satisfaction declines for wives whose husbands lose their jobs are concentrated among second quartile of the household asset income distribution.

${ }^{25}$ For comparison purposes, we also assessed the well-being spillover of spousal unemployment due to his/her own resignation, i.e., voluntary unemployment (Table 18). The coefficient estimate on the spousal unemployment is positive and statistically insignificant in the male partner regression, although the one in the female sub-sample is marginally statistically significant. In line with expectations, the results suggest that spousal voluntary unemployment is generally unassociated with the life satisfaction of the indirectly affected partner. In addition, in Table 18, we also offer results using another proxy for involuntary unemployment entrynamely dismissals - which is less exogenous than plant closings. Nevertheless, the estimates in Table 18 suggest that spousal dismissals are also negatively associated with the indirectly affected spouse's life evaluations, which confirms the argument regarding the psychological costs induced by involuntary unemployment. In addition, the larger coefficient estimates (in absolute value) among female partners whose husbands get dismissed (compared with the original results in Table 1) confirms the more endogenous nature of "dismissals."
} 
Table 7 Effect of one spouse's job loss on the life satisfaction of the other spouse, social norms of unemployment, fixed effects

Male partner

(1)

$\begin{array}{lll}\text { Dependent variable: life satisfaction of the indirectly affected spouse } & \\ \text { Spousal job loss due to plant closure } & -0.384^{* * *} & -0.210^{* *} \\ & (0.110) & (0.099) \\ \text { Indirectly affected spouse unemployed } & -0.845^{* * *} & -0.464^{* * *} \\ & (0.049) & (0.038) \\ \text { Job loss } \times \text { indirectly affected spouse unemp. } & 0.508 & -0.313 \\ & (0.373) & (0.270) \\ \text { State and year dummies } & \mathrm{Y} & \mathrm{Y} \\ \text { Individual fixed effects } & \mathrm{Y} & \mathrm{Y} \\ \text { Individual controls } & \mathrm{Y} & \mathrm{Y} \\ \text { No. observations } & 51,816 & 62,903 \\ \text { Adjusted } \mathrm{R}^{2} & 0.548 & 0.514 \\ \text { No. individuals (couples) } & 10,682 & 12,208\end{array}$

Female partner

(2)

Source: Authors' calculations based on GSOEP 1991-2015. Notes: Robust standard errors in parentheses, clustered at the individual level: $* * * p<0.01, * * p<0.05, * p<0.1$. The analyses exclude 1999 and 2000 as the reasons for job termination question excluded the plant closure response. Additionally, 1993 is excluded as the doctor visits question was not asked then

exist at the couple level. Like the life evaluations variable, the regressands in Table 8 are subjective assessments of the different life aspects measured on a $0-10$ scale.

We provide some intuition about the expected results. First, concerning the regressions using satisfaction with housework as the dependent variable, the gender identity hypothesis (Akerlof and Kranton 2000) posits that individuals derive "identity utility" from adhering to social norms. Thus, upon becoming unemployed, men-traditionally viewed as "breadwinners" - may shy away from housework, while unemployed women may substitute market work with household work (Grogan and Koka 2013). Therefore, we expect that satisfaction with household work would increase for indirectly affected men (whose wives enter unemployment) but remain unchanged or decrease for indirectly affected women. ${ }^{26}$ Second, if spouses have a complementarity in leisure and value time spend together more than income or social status, then satisfaction with free time for the indirectly affected spouse could increase following spousal job loss. This expectation is also inspired by the finding in Chadi and Hetschko (2017) that satisfaction with free time and family life increases for those who themselves become unemployed. Third, given that the consequences of unemployment are largely non-pecuniary and that unemployment benefits in Germany are relatively high in the first year of unemployment, we expected no effects of spousal job loss on

\footnotetext{
${ }^{26}$ An alternative test for the "identity utility" hypothesis would be to check the heterogeneity across immigrant groups, whereby different social norms related to the more traditional division of labor within the household are arguably in place. However, the small number of observations of immigrant groups in our analysis sample and the GSOEP in general limits our ability to credibly execute such an exercise.
} 


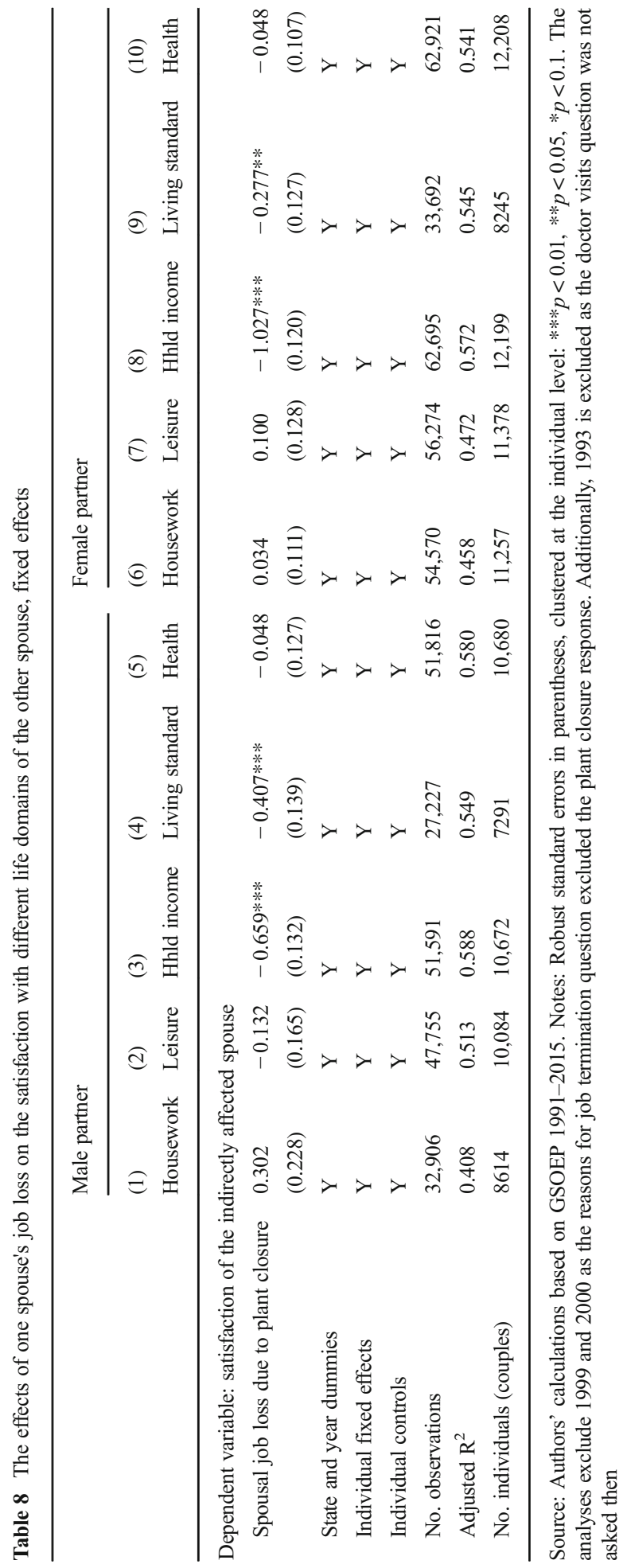


satisfaction with household income and satisfaction with living standards unless the satisfaction comes from the subjective valuation of labor income. Finally, given the finding in Marcus (2013) that spousal unemployment affects the indirectly affected partner's mental health, we anticipated that spousal unemployment attracts negative coefficient estimates for both genders in the health satisfaction regressions.

Consistent with our expectations, Table 8 shows that while spousal involuntary unemployment is negatively associated with the other partner's health satisfaction, the relationship is positive between unemployment and housework satisfaction, although both coefficient estimates are statistically insignificant. The null impact of spousal job loss on health satisfaction is in line with Schmitz (2011), who shows that plant closings do not affect individual health satisfaction. While unemployed individuals increase their time spent in housework (Chadi and Hetschko 2017), this increase in home production does not translate into increased housework satisfaction among their partners.

In addition, as noted above, spousal unemployment could be positively associated with leisure satisfaction if indirectly affected partners value their time spent together more than household income or social status associated with employment. Despite the statistical insignificance, the negative sign of the coefficient estimate on unemployment in the leisure satisfaction regressions in the male sample (Model (2) in Table 8) implies that the loss of income and the social status concerns dominate the leisure complementarity between spouses. The opposite conclusion holds true in the female sample (Model (7) in Table 8), again despite the statistical insignificance of the spousal unemployment variable.

Nevertheless, the main insight from Table 8 is that spousal job loss due to firm closure strongly reduces the other partner's satisfaction with household income and satisfaction with living standards. Indirectly affected men's income satisfaction declines by 0.7 points, which is enormous compared to the corresponding overall life satisfaction loss triggered by spousal unemployment. The corresponding losses for indirectly affected wives are even greater, being about one point on a $0-10$ scale. These large coefficient estimates at the couple level are similarly documented at the individual level by Chadi and Hetschko (2017), who report income satisfaction declines of about 1.6 points (on a $0-10$ scale) following one's own unemployment. Table 8 also demonstrates that satisfaction with living standards declines by about 0.4 points for male partners and by 0.3 points for female partners.

These results suggest that both genders experience a deterioration in their household's perceived financial well-being, but not in terms of other life aspects. Upon first glance, this finding may appear at odds with our result that income does not explain the life satisfaction loss associated with spousal joblessness. Our explanation hinges on modifying the argument in Chadi and Hetschko (2017), who explain for the negative income satisfaction coefficient associated with individual unemployment with the disutility of not earning labor income. Specifically, couples in which one spouse is unemployed likely cover their consumption needs with the earnings of the other spouse or via income from public transfers. Thus, while the cross-spouse psychological costs of unemployment are independent of income, the large income satisfaction declines shown in Table 8 could be due to the loss of spousal labor income and the stigma effects associated with unemployment and living on public welfare (Chadi and Hetschko 2017). Thus, the negative coefficient estimates for these perceived financial well-being variables likely reflect the disutility of having a partner who fails to comply with the social norm of working and earning a living (Stutzer \& Lalive 2004). This 


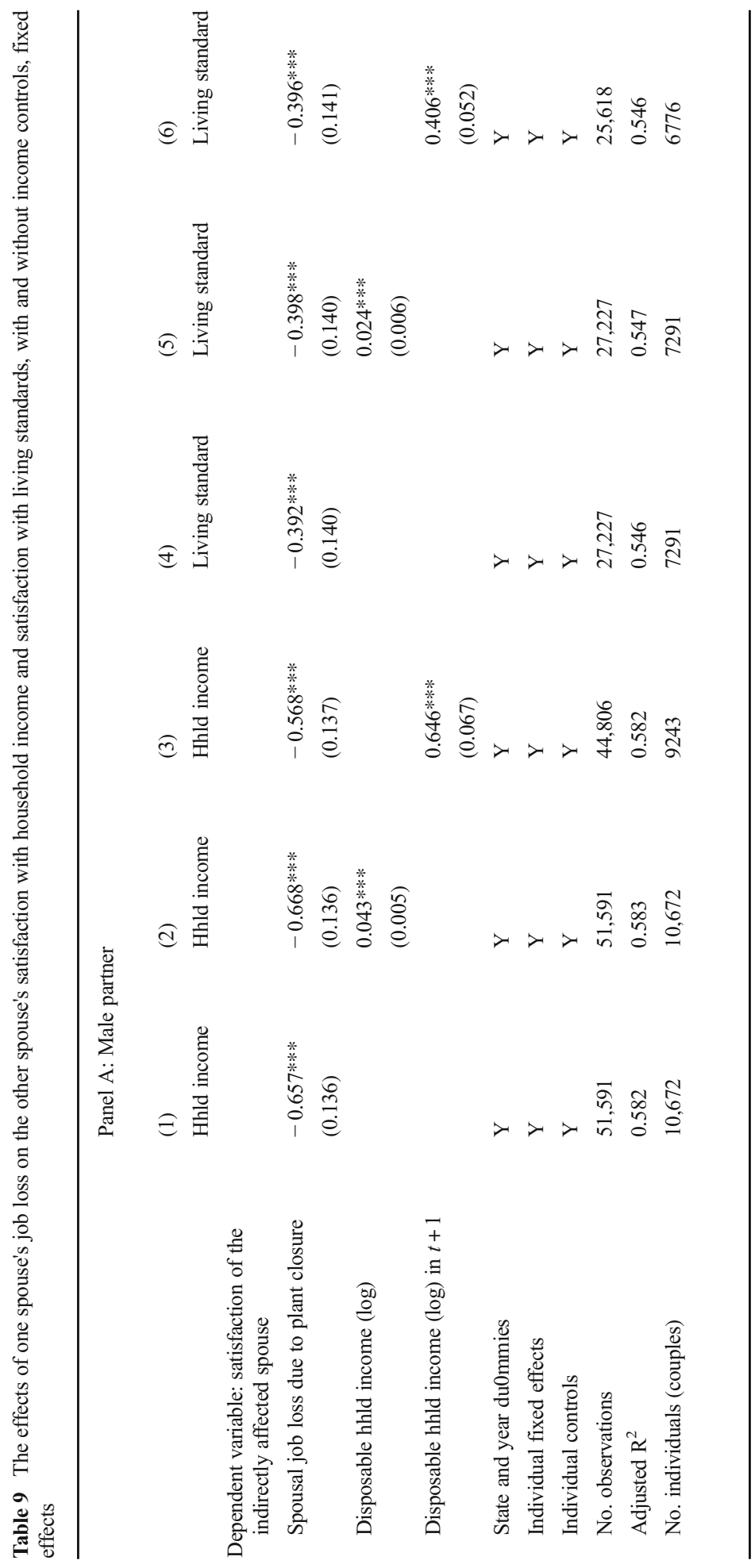




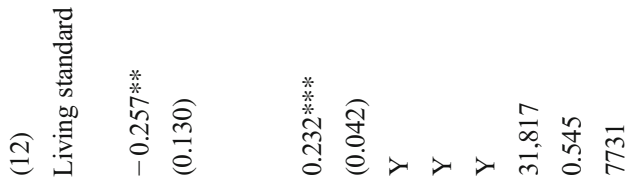

올

i.

*

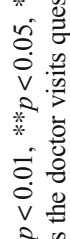

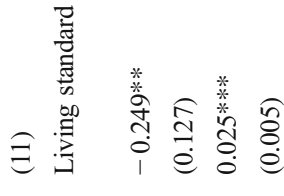

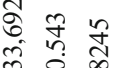

政

$\lambda>\lambda$ लंखे

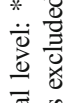

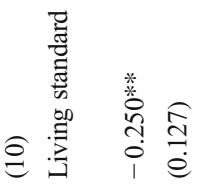

?ำ

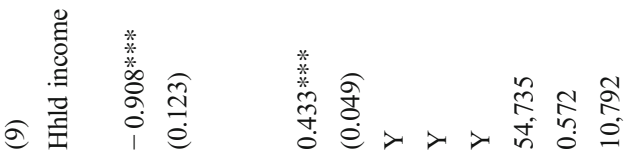

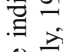

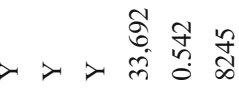

恋.

릉

$\ddot{\Xi} \infty$

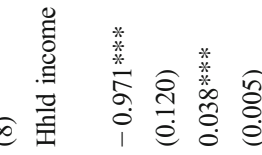

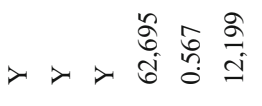

昰

के के

흘을

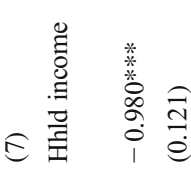

急 
reasoning further explains the larger negative coefficient estimate for women whose husbands become unemployed, highlighting the social norm of husbands as the breadwinners.

In subsequent analyses, we investigate whether the decline in satisfaction with income and standard of living is driven by an income effect. Specifically, in Table 9 we present results whereby in separate regressions we exclude the household income variable and control for household asset income as well as income in the next time period. Evidently, for both genders and when satisfaction with both household income and living standards are the dependent variables, the coefficient estimates on spousal unemployment do not differ much depending on whether we include or exclude income or whether we control for household asset income or future income. These results are in line with the findings in Table 1 and suggest that the actual financial conditions (current and future) do not drive our effects; rather, the well-being consequences of unemployment that we document are likely attributable to the worsened perception about the financial situation and the subsequent psychological burden imposed on the partners of the unemployed.

\subsection{Anticipation of and adaptation to spousal unemployment}

Earlier work provides strong empirical evidence of both lead and lagged effects of one's own unemployment on current life satisfaction. According to Clark and Georgellis (2013), while life satisfaction normalizes (although it does not necessarily return to baseline) after some life events, there is no adaptation to unemployment among males. To evaluate the degree of anticipation and adaptation to spousal involuntary unemployment, we estimate the model described in Eq. (2) using the leads and lags of the unemployment indicator. As explained in Section 3, the estimation of Eq. (2) is based on the treated sample in which directly affected spouses lose their jobs due to plant closure. Therefore, one should be cautious in comparing the results with those from our main specifications (i.e., Tables 1-9) which rely on a much larger sample (namely, including both treated and comparison couples).

Figure 1 illustrates the spousal life satisfaction patterns before and after the other partner becomes unemployed due to plant closure. The left panel of the graph refers to the "husband sample" (whereby the female spouse becomes unemployed) and the right panel illustrates the results from the "wife sample" (whereby the male partner experiences a plant closure). The results suggest strong lead and lagged effects of unemployment for female partners. Importantly, indirectly affected wives' life satisfaction does not bounce back to the baseline score two years after husbands' unemployment, suggesting that there is no adaptation to unemployment for this group. The picture is less clear-cut for male partners whose wives lose their jobs due to plant closures. The confidence intervals are notably larger for the "husband sample" due to the smaller sample size within the observation period (compared with the "wife sample").

For comparison purposes, Fig. 2 still relies on the couple sample but shows the results of one's own life satisfaction patterns before and after involuntary unemployment over the same period. The results are in line with those documented by Clark and Georgellis (2013). When men experience job loss, we find evidence of no adaptation of life satisfaction to their own unemployment, whereas the picture is again not so clear-cut when women become jobless. The imprecise estimates in the cases when women become jobless in Figs. 1 and 2 are attributed to the small number of "treated" observations (i.e., 
Spousal life satisfaction patterns
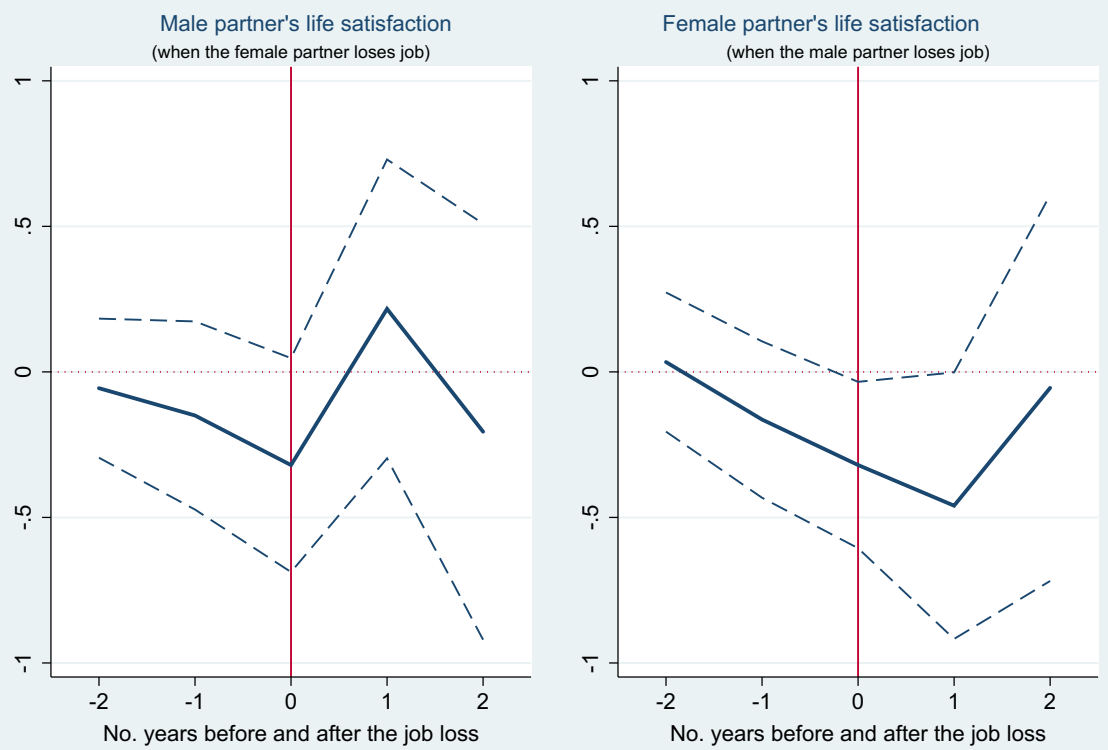

Fig. 1 Source: authors based on GSOEP 1991-2015. Notes: the figure shows the coefficient estimates of the lead and lagged unemployment dummies from the estimation of Eq. (2). The left panel refers to the "husband sample" (whereby the female spouse gets unemployed) and the right panel illustrates the results for the "wife sample" (whereby the male partner experiences a plant closure). While the dashed lines refer to the 95\% confidence interval, the solid line denotes the coefficient estimates of $\left\{U^{S}{ }_{-2}, U^{S}{ }_{-1}, U^{S}, U^{S}{ }_{1}, U^{S}\right\}$ specified in Eq. (2). Accordingly, the $\mathrm{x}$-axis on the range of $[-2,2]$ refers to the number of years before and after the partner gets unemployed, and the vertical solid line (crossing 0 ) illustrates the time of entry into unemployment. The y-axis denotes the life satisfaction outcome. The reference category is $U_{-3}^{S}$. Given the fixed effects estimation, the coefficient estimates should be interpreted as the change in life satisfaction (within a person) with respect to the score three (or more) years before the partner gets unemployed due to plant closure

fewer women than men lose their jobs due to plant closures, see also Table 11 in Appendix A). Thus, we show the female sample results for illustrative purposes but refrain from drawing solid conclusions about anticipation and adaptation patterns.

\section{Conclusion}

Personal unemployment has large psychological costs that extend beyond the mere income loss. In this paper, we use representative German household panel data with information on exogenous unemployment entry to provide causal evidence that the non-pecuniary costs of unemployment are also borne by spouses. Husbands' life satisfaction drops by about 0.34 points following their spouse's unemployment, while the life satisfaction of wives whose partner becomes unemployed drops by about 0.25 points (on a $0-10$ scale). The suffering imposed on the partners is large and would require compensations of about 49,000 Euros for indirectly affected males and about 52,000 Euros for indirectly affected females to bring spouses to their previous wellbeing levels. While men largely appear to adapt to their wives' unemployment, women 
Own life satisfaction patterns
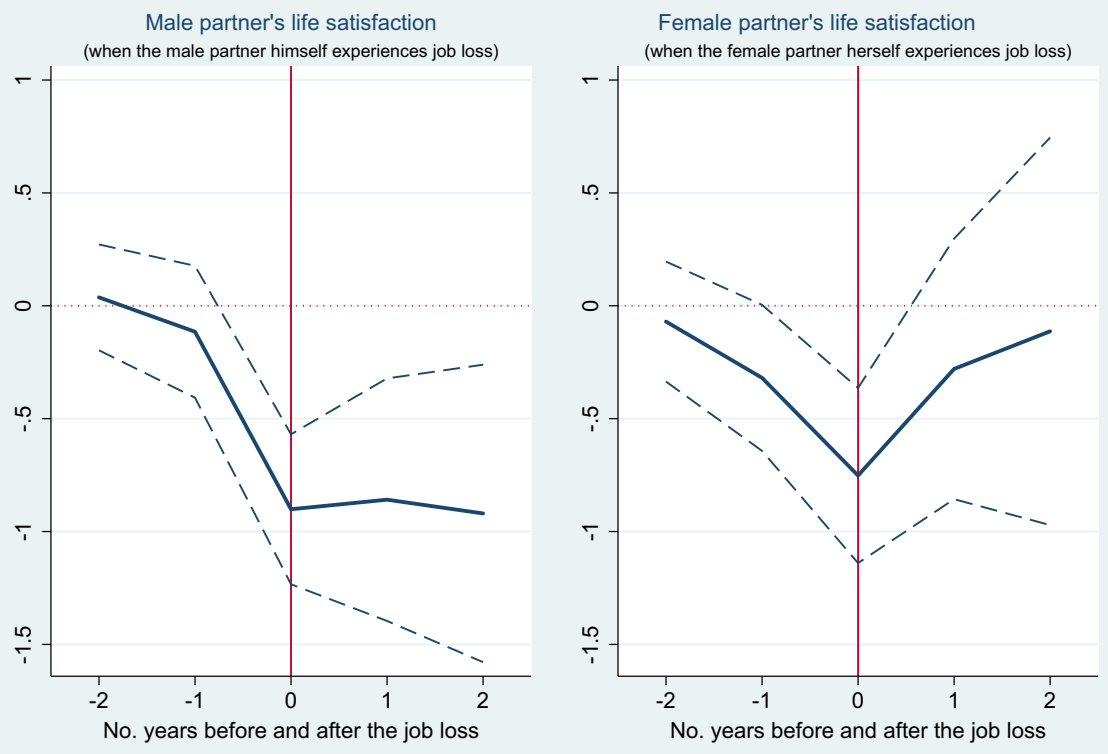

Fig. 2 Source: authors based on GSOEP 1991-2015. Notes: the figure shows the coefficient estimates of the lead and lagged unemployment dummies from the estimation of Eq. (2) for directly affected individuals. The left panel refers to cohabiting husbands who themselves get unemployed and the right panel illustrates the results for wives who themselves experience plant closure. While the dashed lines refer to the $95 \%$ confidence interval, the solid line denotes the coefficient estimates of $\left\{U_{-2}^{S}, U^{S}{ }_{-1}, U_{0}^{S}, U_{1}^{S}, U_{2}^{S}\right\}$ specified in Eq. (2). Accordingly, the $\mathrm{x}$-axis on the range of $[-2,2]$ refers to the number of years before and after unemployment, and the vertical solid line (crossing 0 ) illustrates the time of entry into unemployment. The y-axis denotes the life satisfaction outcome. The reference category is $U_{-3}^{S}$. Given the fixed effects estimation, the coefficient estimates should be interpreted as the change in life satisfaction (within a person) with respect to the score three (or more) years before the entering unemployment due to plant closure

whose husbands experienced plant closures suffer life satisfaction declines even three years after unemployment. Our results are robust to a number of sensitivity checks, including controlling for the job loss anticipation, accounting for panel attrition, couple dissolution, and regional shocks.

As in the case of individual unemployment, the estimated effects are independent of income but result in large declines in perceived financial situation. Similar to Chadi and Hetschko (2017), we interpret the large dissatisfaction with income and living standards following spousal unemployment as a marker of the high value attached to market work, the disutility of living on public assistance, and accordingly, the social stigma of being jobless. Overall, these findings imply that the large non-pecuniary costs of spousal unemployment are due to psychological scarring from the unemployment experience itself.

Our analysis has several policy implications. First, policies aimed at alleviating the consequences of unemployment should also consider other household members and especially female partners. Second, in the spirit of Bubonya et al. (2017), we argue that unemployment policies that simply provide monetary assistance are unlikely to restore affected families' well-being. At the same time, policies that seek to reduce the psychological burden related to the stigma of being unemployed or receiving 
unemployment benefits could be a double-edged sword if they prolong the unemployment duration. Finally, our findings are also informative to employers who may want to consider a household perspective when designing severance packages. They should be aware that lay-offs scar not only workers but also their families, while the negative psychological effects could be long-lasting.

Acknowledgements This paper first appeared as IZA Discussion Paper No. 10411 in December 2016 and SOEPpaper 891/2016 and should be replaced with the current version, which is substantively new. We thank the Editor Erdal Tekin and two anonymous referees for substantive feedback and suggestions. We are also grateful to Adrian Chadi, Carol Graham, Andrew Clark, Conchita D'Ambrosio, Clemens Hetschko, Boris Nikolaev, Deborah Cobb-Clark, Arnaud Chevalier, Marco Caliendo, Tommaso Colussi, Peter Kuhn, and participants at the Subjective Survey Data in Labour Market Research workshop in Trier, EALE 2017 Conference in St. Gallen, and the IZA Brown Bag for helpful comments and suggestions. Margard Ody helped locating literature, Richard Forsythe provided copy-editing support, and Sarah Stahlmann and Daria Golokhvastova furnished research assistance. The authors are also grateful to the data services of the IDSC of IZA for access to the German Socio-Economics Panel dataset. All errors are our own. The paper was written while both authors were Research Associates at the Institute of Labor Economics (IZA).

\section{Compliance with ethical standards}

Conflict of interest The authors declare that they have no conflict of interest.

\section{Appendix A}

Table 10 Variable definitions

\begin{tabular}{|c|c|}
\hline Variable & Definition \\
\hline \multicolumn{2}{|l|}{ Dependent variables } \\
\hline Life satisfaction & $\begin{array}{l}\text { Overall life satisfaction on a 11-point scale: [0] Completely dissatisfied to } \\
\text { [10] Completely satisfied }\end{array}$ \\
\hline \multicolumn{2}{|l|}{ Life satisfaction domains } \\
\hline Housework & $\begin{array}{l}\text { Satisfaction with housework on a 11-point scale: [0] Completely dissatisfied } \\
\text { to [10] Completely satisfied }\end{array}$ \\
\hline Leisure & $\begin{array}{l}\text { Satisfaction with amount of leisure time on a 11-point scale: [0] Completely } \\
\text { dissatisfied to [10] Completely satisfied }\end{array}$ \\
\hline Hhld income & $\begin{array}{l}\text { Satisfaction with household income on a 11-point scale: [0] Completely } \\
\text { dissatisfied to [10] Completely satisfied }\end{array}$ \\
\hline Living standards & $\begin{array}{l}\text { Satisfaction with standard of living on a 11-point scale: [0] Completely } \\
\text { dissatisfied to [10] Completely satisfied }\end{array}$ \\
\hline Health & $\begin{array}{l}\text { Satisfaction with health on a 11-point scale: [0] Completely dissatisfied to } \\
\text { [10] Completely satisfied }\end{array}$ \\
\hline \multicolumn{2}{|l|}{ Independent variables } \\
\hline \multicolumn{2}{|l|}{ Key regressor } \\
\hline $\begin{array}{l}\text { Spousal job loss due to } \\
\text { plant closure }\end{array}$ & $\begin{array}{l}1=\text { job terminated due to workplace closure among those privately } \\
\text { employed in previous time period, } 0=\text { employed as a private employee }\end{array}$ \\
\hline \multicolumn{2}{|c|}{ Socio-economic characteristics } \\
\hline Age & Age in years \\
\hline Years of education & Number of years of education \\
\hline
\end{tabular}


Table 10 (continued)

\begin{tabular}{|c|c|}
\hline Variable & Definition \\
\hline Private employee & $\begin{array}{l}1=\text { private employee including } 20 \text { occupational position categories, } 0= \\
\text { other types of occupational positions }\end{array}$ \\
\hline Pensioner & $1=$ pensioner, $0=$ other types of occupational positions \\
\hline Registered unemployed & $1=$ registered unemployed, $0=$ other types of occupational positions \\
\hline Not employed & $1=$ not employed, $0=$ other types of occupational positions \\
\hline Self-employed & $\begin{array}{l}1=\text { self-employed including } 13 \text { categories of occupational position, } 0= \\
\text { other types of occupational positions }\end{array}$ \\
\hline Civil servant & $\begin{array}{l}1=\text { civil servant including } 4 \text { categories of occupational position, } 0=\text { other } \\
\text { types of occupational positions }\end{array}$ \\
\hline Currently in education & $1=$ in education, $0=$ other types of occupational positions \\
\hline Currently in military & $\begin{array}{l}1=\text { military and community service, } 0=\text { other types of occupational } \\
\text { positions }\end{array}$ \\
\hline Annual work hours & Annual work hours of individual \\
\hline Annual doctor visits & Annual doctor visits of individual \\
\hline Disabled & $1=$ disabled, $0=$ not disabled \\
\hline
\end{tabular}

Household characteristics

No. persons in the
household
No. children in the
household
Home ownership
Disposable household
income
Household income from
asset flows

West Germany

State dummies

Year dummies

ROR dummies
Number of persons in the household

Number of children in the household

$1=$ owner of dwelling, $0=$ not owner of dwelling

Household post-government income (in 2011 Euros)

Household income from savings, dividends, and rents (in 2011 Euros)

$1=$ reside in west Germany, $0=$ reside in east Germany

Dummy variables for 16 federal states

Dummy variables for years 1991-2013

Dummy variables for 96 German regional policy regions (ROR)

Controls for the robustness checks

Lag of job loss expectation Directly affected spouse expects to lose job in next 2 years, on a 4-point scale: [1] unlikely, [2] probably not, [3] probably, [4] certain

Not in sample in $t+1$

$1=$ respondent is not surveyed in subsequent year, $0=$ available response in subsequent survey year

Spouse's current unemployment duration

The duration (in months) of the current unemployment spell (coded as 0 for the control group)

Divorced/separated in $t+1 \quad 1=$ respondent is divorced or separated in subsequent year, $0=$ otherwise

Children in the household $1=$ presence of children in the household, $0=$ no children in the household

Formally married $\quad 1=$ married, $0=$ cohabiting

ROR-level unemployment Unemployment rate at the level of German regional policy regions (ROR) rate

Source: Authors based on GSOEP Codebooks 


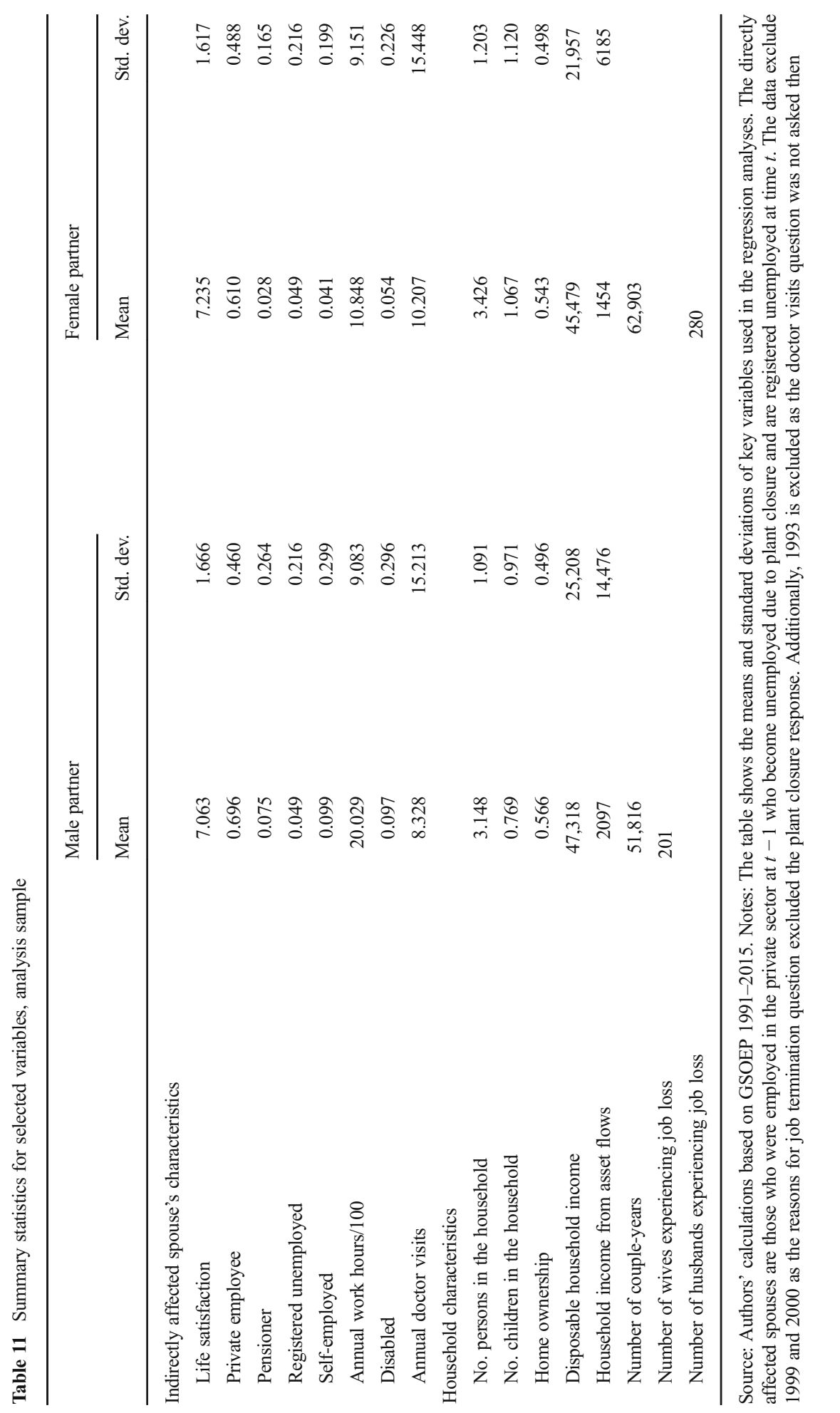




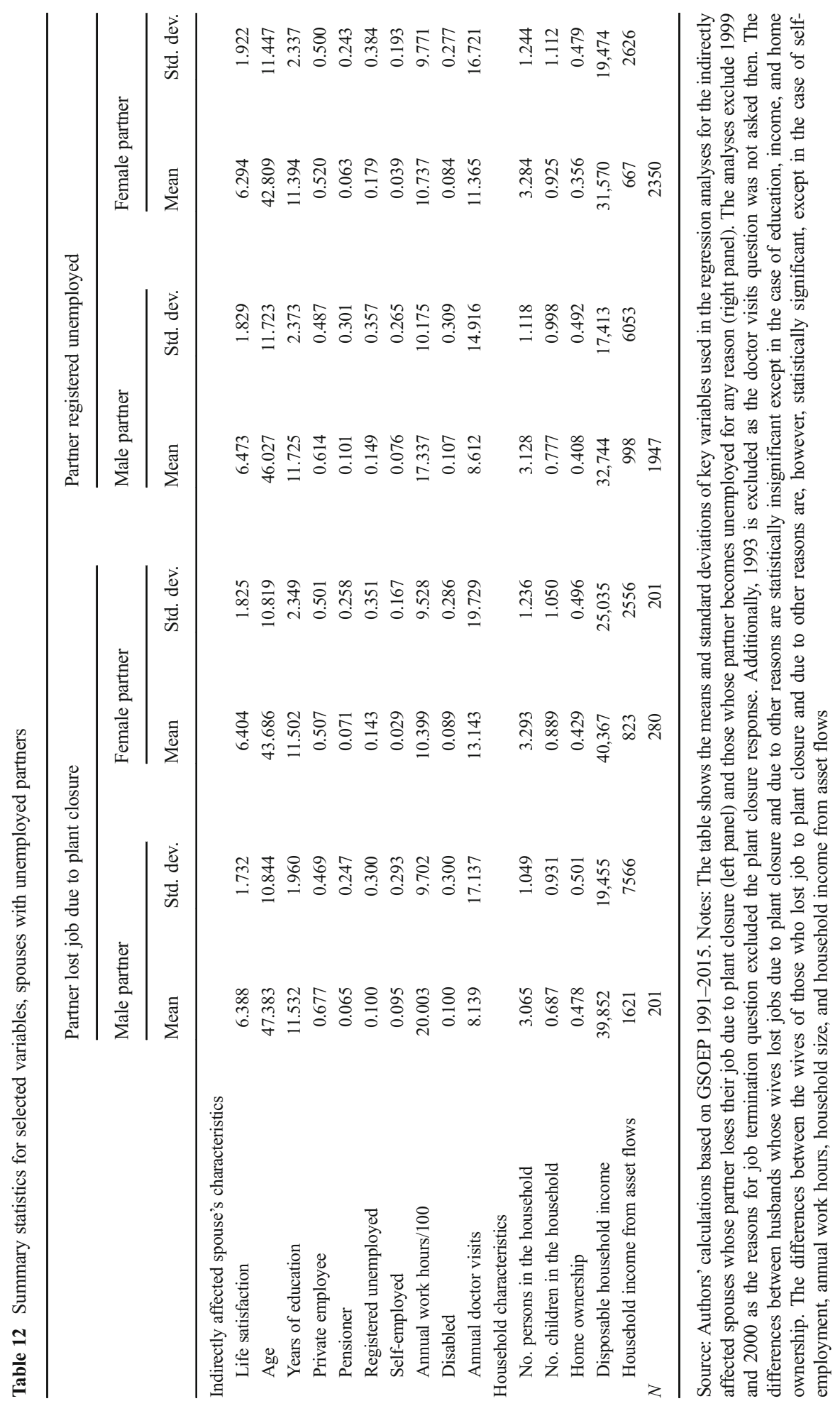




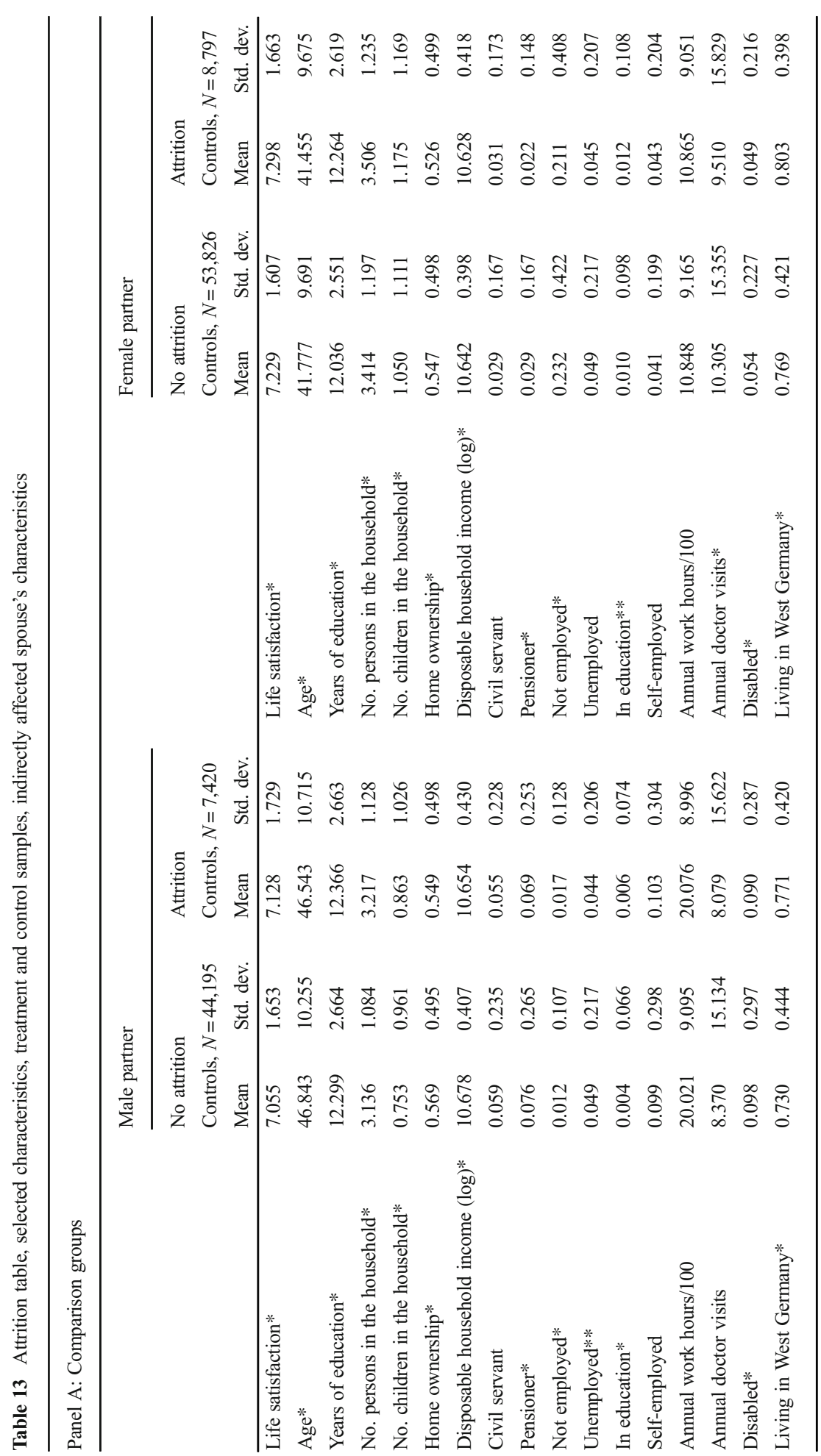




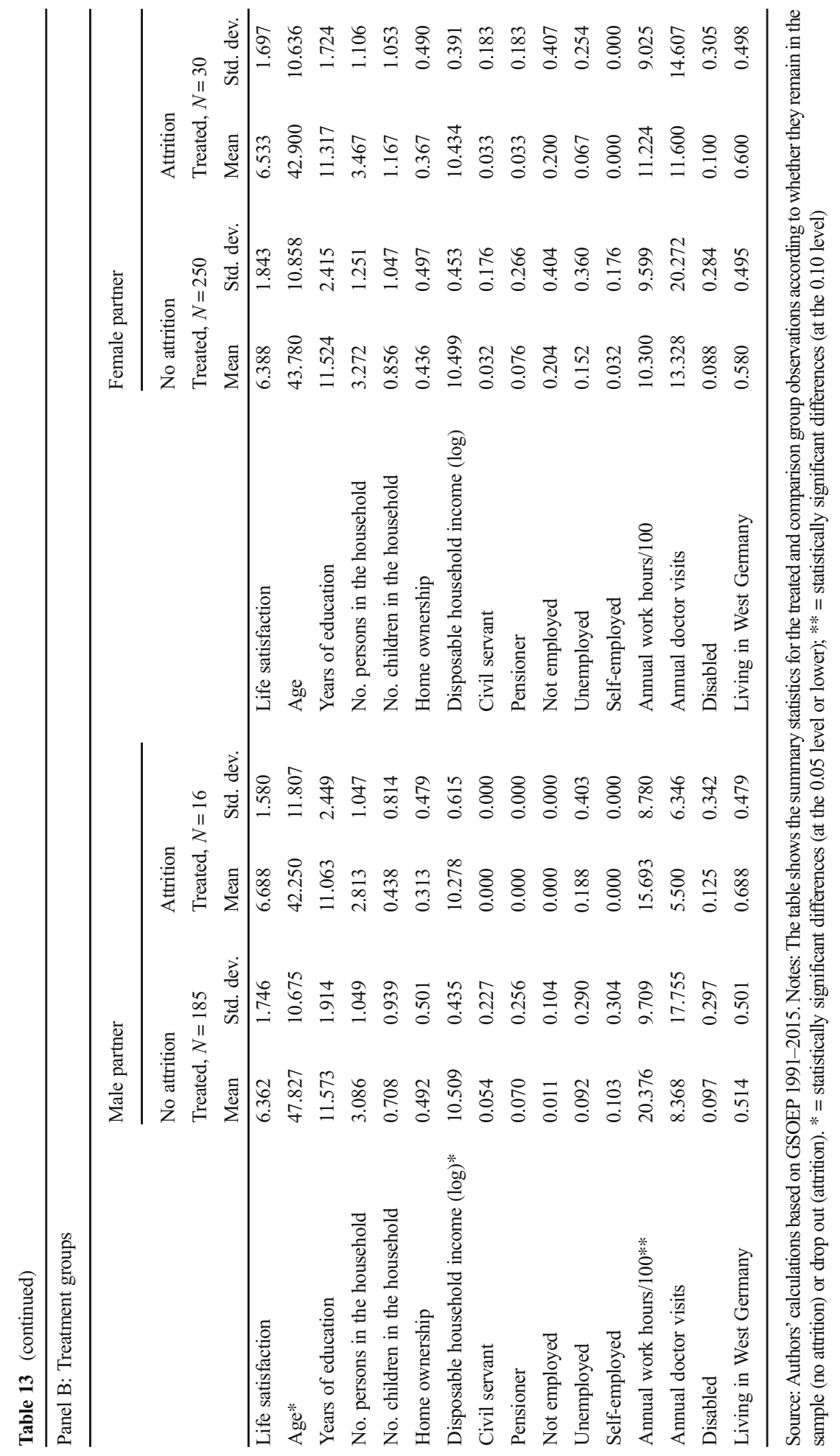


In Table 12, we compare the observable characteristics of spouses whose partners lost their jobs due to a plant closure with those whose partners are registered unemployed for any reason. The table suggests that husbands whose wives experienced plant closure are similar to husbands with unemployed wives. The differences that are statistically significant at the $1 \%$ concern annual work hours and household income. The right panel of Table 12 further shows that wives whose husbands experienced company closures are also similar to the sample of wives with unemployed partners. The statistically significant differences at the $1 \%$ concern home ownership and household income. Some further differences are statistically significant at the $10 \%$ level. While we acknowledge these differences, we cannot directly address them.

\section{Appendix B}

Table 14 Effect of own job loss due to plant closure on own life satisfaction, fixed effects

\begin{tabular}{|c|c|c|c|c|c|c|}
\hline & \multicolumn{3}{|l|}{ Males } & \multicolumn{3}{|l|}{ Females } \\
\hline & (1) & (2) & (3) & (4) & $(5)$ & (6) \\
\hline \multicolumn{7}{|l|}{ Dependent variable: own life satisfaction } \\
\hline Job loss due to plant closure & $\begin{array}{l}-0.953 * * * \\
(0.113)\end{array}$ & $\begin{array}{l}-0.949 * * * \\
(0.113)\end{array}$ & $\begin{array}{l}-0.978^{* * *} \\
(0.113)\end{array}$ & $\begin{array}{l}-0.836^{* * *} \\
(0.116)\end{array}$ & $\begin{array}{l}-0.840^{* * *} \\
(0.116)\end{array}$ & $\begin{array}{l}-0.844 * * * \\
(0.116)\end{array}$ \\
\hline State and year dummies & $\mathrm{Y}$ & $\mathrm{Y}$ & $\mathrm{Y}$ & $\mathrm{Y}$ & $\mathrm{Y}$ & $\mathrm{Y}$ \\
\hline Individual fixed effects & $\mathrm{Y}$ & $\mathrm{Y}$ & $\mathrm{Y}$ & $\mathrm{Y}$ & $\mathrm{Y}$ & $\mathrm{Y}$ \\
\hline Individual controls & $\mathrm{Y}$ & $\mathrm{Y}$ & $\mathrm{Y}$ & $\mathrm{Y}$ & $\mathrm{Y}$ & $\mathrm{Y}$ \\
\hline $\begin{array}{l}\text { Household income from asset flows } \\
\text { control }\end{array}$ & $\mathrm{N}$ & $\mathrm{Y}$ & $\mathrm{N}$ & $\mathrm{N}$ & $\mathrm{Y}$ & $\mathrm{N}$ \\
\hline Disposable income control & $\mathrm{N}$ & $\mathrm{N}$ & $\mathrm{Y}$ & $\mathrm{N}$ & $\mathrm{N}$ & $\mathrm{Y}$ \\
\hline No. observations & 65,597 & 65,597 & 65,597 & 55,925 & 55,925 & 55,925 \\
\hline Adjusted $\mathrm{R}^{2}$ & 0.524 & 0.525 & 0.525 & 0.514 & 0.515 & 0.515 \\
\hline No. individuals (couples) & 12,608 & 12,608 & 12,608 & 11,494 & 11,494 & 11,494 \\
\hline
\end{tabular}

Source: Authors' calculations based on GSOEP 1991-2015. Notes: Robust standard errors in parentheses, clustered at the individual level: $* * * p<0.01$, ** $p<0.05, * p<0.1$. The analyses exclude 1999 and 2000 as the reasons for job termination question excluded the plant closure response. Additionally, 1993 is excluded as the doctor visits question was not asked then 
Table 15 Effect of one spouse's job loss on the life satisfaction of the other spouse, gender effects

(1)

$\begin{array}{lc}\text { Dependent variable: life satisfaction of the indirectly affected spouse } & -0.346^{* * *} \\ \text { Spousal job loss due to plant closure } & (0.105) \\ & 0.099 \\ \text { Spousal job loss } \times \text { female } & (0.140) \\ \text { State and year dummies } & \mathrm{Y} \\ \text { Individual fixed effects } & \mathrm{Y} \\ \text { Individual controls } & \mathrm{Y} \\ \text { No. observations } & 114,719 \\ \mathrm{R}^{2} & 0.624 \\ \text { No. individuals (couples) } & 22,890\end{array}$

Source: Authors' calculations based on GSOEP 1991-2015. Notes: Robust standard errors in parentheses, clustered at the household level: $* * * p<0.01, * * p<0.05, * p<0.1$. The analyses exclude 1999 and 2000 as the reasons for job termination question excluded the plant closure response. Additionally, 1993 is excluded as the doctor visits question was not asked then

Table 16 Effect of one spouse's job loss on the life satisfaction of the other spouse, ROR-level unemployment, fixed effects

\begin{tabular}{|c|c|c|c|c|c|c|}
\hline & \multicolumn{3}{|c|}{ Male partner } & \multicolumn{3}{|c|}{ Female partner } \\
\hline & $(1)$ & (2) & (3) & (4) & $(5)$ & (6) \\
\hline \multicolumn{7}{|c|}{ Dependent variable: life satisfaction of the indirectly affected spouse } \\
\hline Spousal job loss due to plant closure & $\begin{array}{c}-0.173 \\
(0.156)\end{array}$ & $\begin{array}{c}-0.172 \\
(0.155)\end{array}$ & $\begin{array}{l}-0.536^{*} \\
(0.313)\end{array}$ & $\begin{array}{l}-0.282^{* *} \\
(0.124)\end{array}$ & $\begin{array}{l}-0.276^{* *} \\
(0.124)\end{array}$ & $\begin{array}{l}-0.463 \\
(0.312)\end{array}$ \\
\hline ROR-level unemployment rate & & $\begin{array}{l}-0.027 * * * \\
(0.009)\end{array}$ & $\begin{array}{l}-0.027^{* * *} \\
(0.009)\end{array}$ & & $\begin{array}{l}-0.031^{* * *} \\
(0.008)\end{array}$ & $\begin{array}{l}-0.031 * * * \\
(0.008)\end{array}$ \\
\hline Spousal job loss $\times$ ROR-level unemp. & & & $\begin{array}{l}0.035 \\
(0.025)\end{array}$ & & & $\begin{array}{l}0.017 \\
(0.023)\end{array}$ \\
\hline State and year dummies & $\mathrm{Y}$ & $\mathrm{Y}$ & $\mathrm{Y}$ & $\mathrm{Y}$ & $\mathrm{Y}$ & $\mathrm{Y}$ \\
\hline Individual fixed effects & $\mathrm{Y}$ & $\mathrm{Y}$ & $\mathrm{Y}$ & $\mathrm{Y}$ & $\mathrm{Y}$ & $\mathrm{Y}$ \\
\hline Individual controls & $\mathrm{Y}$ & $\mathrm{Y}$ & $\mathrm{Y}$ & $\mathrm{Y}$ & $\mathrm{Y}$ & $\mathrm{Y}$ \\
\hline No. observations & 39,670 & 39,670 & 39,670 & 46,700 & 46,700 & 46,700 \\
\hline Adjusted $\mathrm{R}^{2}$ & 0.565 & 0.565 & 0.565 & 0.521 & 0.521 & 0.521 \\
\hline No. individuals (couples) & 9112 & 9112 & 9112 & 10,363 & 10,363 & 10,363 \\
\hline
\end{tabular}

Source: Authors' calculations based on GSOEP and INKAR data 1998, 2001-2014. Notes: Robust standard errors in parentheses: ${ }^{* *} p<0.01,{ }^{*} p<0.05,{ }^{*} p<0.1$. The analyses exclude 1999 and 2000 as the reasons for job termination question excluded the plant closure response. Additionally, 1993 is excluded as the doctor visits question was not asked then. The ROR-level information is only available until 2014 at the time of writing 
Table 17 Effect of one spouse's job loss on the life satisfaction of the other spouse, weighted results, fixed effects

Male partner

(1)
Female partner

(2)

$\begin{array}{llc}\text { Dependent variable: life satisfaction of the indirectly affected spouse } & \\ \text { Spousal job loss due to plant closure } & -0.381^{* * *} & -0.299^{* *} \\ & (0.129) & (0.117) \\ \text { State and year dummies } & \mathrm{Y} & \mathrm{Y} \\ \text { Individual fixed effects } & \mathrm{Y} & \mathrm{Y} \\ \text { Individual controls } & \mathrm{Y} & \mathrm{Y} \\ \text { No. observations } & 48,870 & 59,948 \\ \text { Adjusted } \mathrm{R}^{2} & 0.533 & 0.498 \\ \text { No. individuals (couples) } & 9858 & 11,458\end{array}$

Source: Authors' calculations based on GSOEP 1991-2015. Notes: Robust standard errors in parentheses, clustered at the individual level: $* * * p<0.01,{ }^{* *} p<0.05,{ }^{*} p<0.1$. The analyses exclude 1999 and 2000 as the reasons for job termination question excluded the plant closure response. Additionally, 1993 is excluded as the doctor visits question was not asked then. The regressions use the sample weight

Table 18 Effect of one spouse's voluntary job loss and dismissal on the life satisfaction of the other spouse, fixed effects

Male partner Female partner Male partner Female partner

Spousal job loss due to own resignation Spousal job loss due to dismissal

(1)

(2)

(3)

(4)

Dependent variable: life satisfaction of the indirectly affected spouse

$\begin{array}{lllll}\text { Spousal job loss } & 0.043 & -0.300^{*} & -0.261^{* * * *} & -0.675^{* * * *} \\ & (0.109) & (0.177) & (0.066) & (0.073) \\ \text { State and year dummies } & \mathrm{Y} & \mathrm{Y} & \mathrm{Y} & \mathrm{Y} \\ \text { Individual fixed effects } & \mathrm{Y} & \mathrm{Y} & \mathrm{Y} & \mathrm{Y} \\ \text { Individual controls } & \mathrm{Y} & \mathrm{Y} & \mathrm{Y} & \mathrm{Y} \\ \text { No. observations } & 51,819 & 62,737 & 52,233 & 52,233 \\ \text { Adjusted } \mathrm{R}^{2} & 0.544 & 0.513 & 0.544 & 0.516 \\ \text { No. individuals (couples) } & 10,699 & 12,199 & 10,758 & 10,736\end{array}$

Source: Authors' calculations based on GSOEP 1991-2015. Notes: Robust standard errors in parentheses, clustered at the individual level: $* * * p<0.01, * * p<0.05, * p<0.1$. The number of wives who voluntary quit their jobs in Model (1) is 204. The number of wives who get dismissed in Model (3) is 618. The number of husbands who voluntarily quit their jobs in Model (2) is 119, and the number of dismissed husbands in Model (4) is 616. Observations from year 1993 are excluded as the doctor visits question was not asked then 


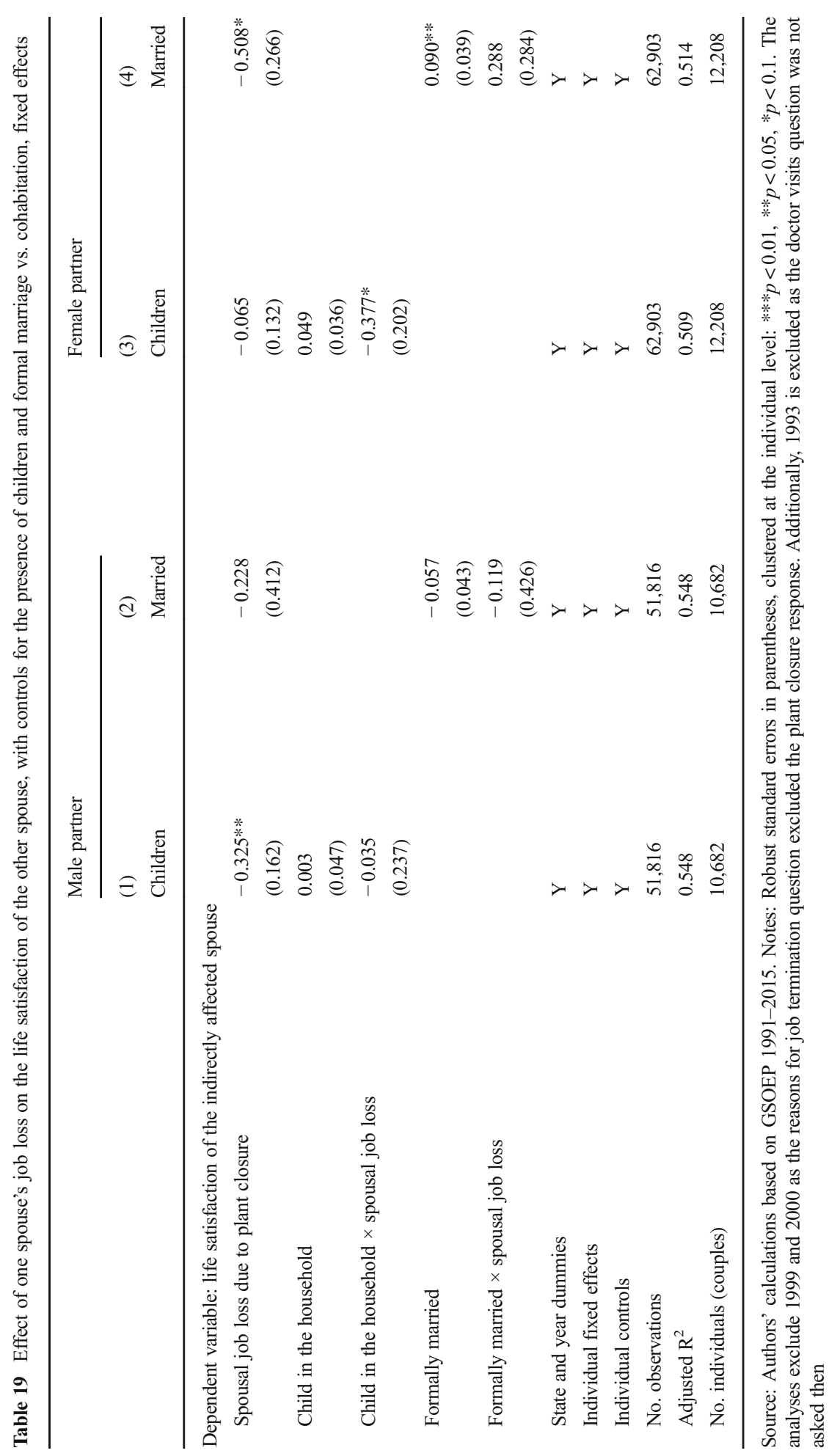




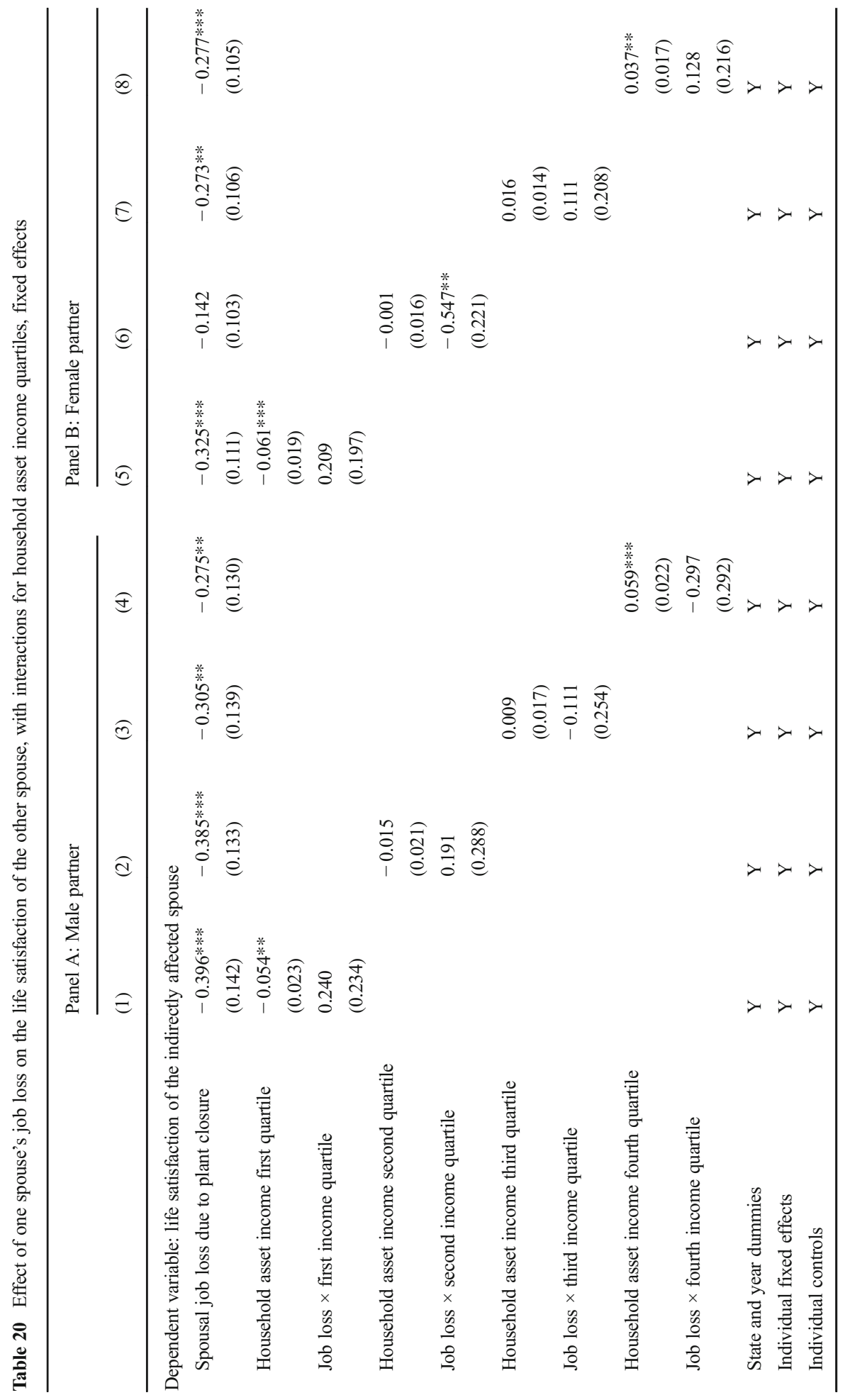




$$
\text { 市 }
$$


As noted in Section 6, our results could be driven by local labor market shocks, such as rising regional unemployment resulting from declining industries, which influence both firm closures and spousal life satisfaction. To ascertain whether this identification threat changes our results, we merged the GSOEP sample with unemployment data at the regional (i.e., ROR) level from the INKAR database, which is currently available until 2014. The unemployment data on the 96 ROR regions in Germany is available starting in 1998. Ideally, we would have wanted to include regional-level (ROR-level) fixed effects but unfortunately this was unfeasible as some RORs do not have any couples experiencing company closings. Instead, we conducted the analyses controlling for the local unemployment rate. Note also that the plant closure variable is not available in 1999 and 2000 and thus these years are excluded from the regressions. The regressions are thus effectively for 1998, 2001-2014. Table 16 presents the results.

In Models (1) and (4), we replicate the baseline results (i.e., those reported in Table 1) for the 1998, 2001-2014 sample. Based on these results, it is clear that this sub-sample differs from the main analysis sample. Table 16, Model (1) shows that the coefficient for spousal job loss is negative but statistically significant, which is unsurprising given the smaller number of treated couples. The results in Model (4), whereby the husband loses his job, remain significant. Adding the regional-level unemployment (Models (2) and (4)), which itself is negatively associated with both male and female partner's life satisfaction, does not change the coefficient estimate on the spousal job loss due to plant closure. Finally, the regional unemployment level has no additional effect on the indirectly affected spouse's well-being when interacted with spousal unemployment in Models (3) and (6). These findings suggest that the results that we identify are not driven by the regional unemployment conditions, at least for the 1998-2014 sub-sample.

Open Access This article is distributed under the terms of the Creative Commons Attribution 4.0 International License (http://creativecommons.org/licenses/by/4.0/), which permits unrestricted use, distribution, and reproduction in any medium, provided you give appropriate credit to the original author(s) and the source, provide a link to the Creative Commons license, and indicate if changes were made.

\section{References}

Akerlof GA, Kranton RE (2000) Economics and identity. Q J Econ 115(3):715-753

Avdic D, Chevalier A (2016) Own unemployment, local unemployment and suicide. Working Paper

Browning M, Moller Dano A, Heinesen E (2006) Job displacement and stress-related health outcomes. Health Econ 15(10):1061-1075

Bubonya M, Cobb-Clark DA, Wooden M (2017) Job loss and the mental health of spouses and adolescent children. IZA J Labor Econ 6(1):1-27

Carroll N (2007) Unemployment and Psychological Well-being. Economic Record, 83(262):287-302

Chadi A, Hetschko C (2017) Income or leisure? On the hidden benefits of (un-) employment. Institute of Labour Law and Industrial Relations in the European Union (IAAEU) Working Paper No. 06/2017

Clark AE (2003) Unemployment as a social norm: psychological evidence from panel data. J Labor Econ 21(2):323-351

Clark AE (2016) Adaptation and the Easterlin paradox. In: Tachibanaki T (ed) Advances in happiness research. Springer, Berlin, pp 75-94

Clark AE, Georgellis Y (2013) Back to baseline in Britain: adaptation in the British household panel survey. Economica 80(319):496-512

Clark AE, Oswald AJ (1994) Unhappiness and unemployment. Econ J 104(424):648-659 
Clark AE, Oswald AJ (2002) A simple statistical method for measuring how life events affect happiness. Int J Epidemiol 31(6):1139-1144

Clark AE, Georgellis Y, Sanfey P (2001) Scarring: the psychological impact of past unemployment. Economica 68(270):221-241

Couch KA, Placzek DW (2010) Earnings losses of displaced workers revisited. Am Econ Rev 100(1):572589

Davis SJ, Wachter TM v (2011) Recessions and the cost of job loss. Brook Pap Econ Act 2011(2):1-72

Diener E, Suh EM, Lucas RE, Smith HL (1999) Subjective well-being: three decades of progress. Psychol Bull 125(2):276-302

Doiron D, Mendolia S (2012) The impact of job loss on family dissolution. J Popul Econ 25(1):367-398

Eliason M (2012) Lost jobs, broken marriages. J Popul Econ 25(4):1365-1397

Ferrer-i-Carbonell A, Frijters P (2004) How important is methodology for the estimates of the determinants of happiness? Econ J 114(497):641-659

Flèche S, Layard R (2017) Do more of those in misery suffer from poverty, unemployment or mental illness? Kyklos 70(1):27-41. https://doi.org/10.1111/kykl.12129

Frick JR, Jenkins SP, Lillard DR, Lipps O, Wooden M (2007) The Cross-National Equivalent File (CNEF) and its member country household panel studies. Schmollers Jahr 127(4):627-654 http://www.diw. de/sixcms/detail.php/77260

Frijters P, Beatton T (2012) The mystery of the U-shaped relationship between happiness and age. J Econ Behav Organ 82(2):525-542

Gerdtham U-G, Johannesson M (2003) A note on the effect of unemployment on mortality. J Health Econ 22(3):505-518

Gerlach K, Stephan G (1996) A paper on unhappiness and unemployment in Germany. Econ Lett 52(3):325330

Graham C, Nikolova M (2015) Bentham or Aristotle in the development process? An empirical investigation of capabilities and subjective well-being. World Dev 68:163-179

Grogan L, Koka K (2013) Economic crises and wellbeing: social norms and home production. J Econ Behav Organ 92:241-258

Haisken-DeNew J, Frick JR (2005) DTC Desktop Companion to the German Socio-Economic Panel (SOEP): www.diw.de/deutsch/sop/service/dtc/dtc.pdf

Hansen H-T (2005) Unemployment and marital dissolution a panel data study of Norway. Eur Sociol Rev 21(2):135-148

Helliwell JF, Huang H, Wang S (2016) The distribution of world happiness. In JF Helliwell, R Layard, J Sachs (eds) World happiness report 2016. New York, pp 8-48

Kassenboehmer SC, Haisken-DeNew JP (2009) You're fired! The causal negative effect of entry unemployment on life satisfaction. Econ J 119(536):448-462

Kassenboehmer SC, Haisken-DeNew JP (2012) Heresy or enlightenment? The well-being age U-shape effect is flat. Econ Lett 117(1):235-238

Kind M, Haisken-DeNew JP (2012) Unexpected victims: how parents' unemployment affects their children's life satisfaction. Melbourne Institute Working Paper No. 21/12, pp 1-16

Knabe A, Rätzel S (2011a) Quantifying the psychological costs of unemployment: the role of permanent income. Appl Econ 43(21):2751-2763

Knabe A, Rätzel S (2011b) Scarring or scaring? The psychological impact of past unemployment and future unemployment risk. Economica 78(310):283-293

Knabe A, Schöb R, Weimann J (2016) Partnership, gender, and the well-being cost of unemployment. Soc Indic Res 129(3):1255-1275

Kuhn A, Lalive R, Zweimüller J (2009) The public health costs of job loss. J Health Econ 28(6):1099-1115

Luhmann M, Weiss P, Hosoya G, Eid M (2014) Honey, I got fired! A longitudinal dyadic analysis of the effect of unemployment on life satisfaction in couples. J Pers Soc Psychol 107(1):163-180

Marcus J (2013) The effect of unemployment on the mental health of spouses-evidence from plant closures in Germany. J Health Econ 32(3):546-558

Mendolia S (2014) The impact of husband's job loss on partners' mental health. Rev Econ Househ 12(2):277294

OECD (2013) OECD guidelines on measuring subjective well-being: organisation for economic cooperation and development. OECD Publishing

Powdthavee N, Vernoit J (2013) Parental unemployment and children's happiness: a longitudinal study of young people's well-being in unemployed households. Labour Econ 24:253-263

Qari S (2014) Marriage, adaptation and happiness: are there long-lasting gains to marriage? J Behav Exp Econ 50:29-39 
Rege M, Telle K, Votruba M (2007) Plant closure and marital dissolution. Statistics Norway, Research Department Discussion Papers No. 514

Schmitz H (2011) Why are the unemployed in worse health? The causal effect of unemployment on health. Labour Econ 18(1):71-78

Siegel M, Bradley EH, Gallo WT, Kasl SV (2003) Impact of husbands' involuntary job loss on wives' mental health, among older adults. J Gerontol Ser B Psychol Sci Soc Sci 58(1):S30-S37

Socio-Economic Panel (SOEP), data for years 1984-2015, version 32.1, SOEP, 2016

Stutzer A, Lalive R (2004) The role of social work norms in job searching and subjective well-being. J Eur Econ Assoc 2(4):696-719

Sullivan D, Von Wachter T (2009) Job displacement and mortality: an analysis using administrative data. Q J Econ 124(3):1265-1306

Tay L, Diener E (2011) Needs and subjective sell-being around the world. J Pers Soc Psychol 101(2):354-365

Ulloa BFL, Møller V, Sousa-Poza A (2013) How does subjective well-being evolve with age? A literature review. J Popul Ageing 6(3):227-246

Whelan CT (1994) Social class, unemployment, and psychological distress. Eur Sociol Rev 10(1):49-61

Winkelmann R (2014) Unemployment and happiness. IZA World Of Labor (94). https://doi.org/10.15185 /izawol.94

Winkelmann L, Winkelmann R (1995) Happiness and unemployment: a panel data analysis for Germany. Appl Econ Q 41:293-307

Winkelmann L, Winkelmann R (1998) Why are the unemployed so unhappy? Evidence from panel data. Economica 65(257):1-15

Witte HD (1999) Job insecurity and psychological well-being: review of the literature and exploration of some unresolved issues. Eur J Work Org Psychol 8(2):155-177

Wooldridge JM (2002) Econometric analysis of cross section and panel data. The MIT Press 0, 5(1), chapter 17 